\title{
Los abrigos pintados de Helechal: un nuevo conjunto de arte rupestre esquemático en Badajoz
}

\author{
Mª Isabel Martínez Perelló *
}

\section{HISTORIA DEL DESCUBRIMIENTO}

La historia del descubrimiento de los abrigos que aquí damos a conocer se remonta a septiembre de 1982, cuando Don José Merino Martín, «Polín», vecino del pueblo pacense de Helechal, acompañado de algunos amigos redescubre de manera fortuita el Abrigo del Zarzal y el Abrigo Superior del Cerro de Las Moriscas, en la Sierra de Tiros (Helechal,T.M. Benquerencia de la Serena, Badajoz). Estos abrigos habían sido estudiados ya por el abate Breuil ${ }^{1}$ en 1933, olvidándose después su ubicación exacta, por lo que su localización supuso para el señor Merino un estímulo para buscar nuevas estaciones rupestres en la sierra, que se vio incrementado al comenzarse la transformación de esa sierra para ser utilizada como coto de caza privado. Desde entonces y hasta nuestros dias una veintena de nuevos abrigos con pinturas rupestres han sido descubiertos. En mayo de 1990 los vecinos de Helechal pusieron tales hallazgos en conocimiento de la Junta de Extremadura, información que ésta nos remitió para que procediéramos a su estudio?

\section{MARCO FÍSICO Y SITUACIÓN}

Los abrigos se encuentran próximios al pueblo de $\mathrm{Helechal}^{3}$, pequeña

\footnotetext{
* Realiza su tesis doctoral en el Dpto. Prehistoria e Historia Antigua de la U.N.E.D., bajo la dirección del Dr. RIPOLL.

1 BREUIL, H., Les peintures rupestres schématiques de la Peninsule lbèrique, T. II, Lagny, 1933-35, p.86-87, fig. 26, pl.XIX 3b, XXI 2,3 y p.88-94, fig.27-30, pl.XXI 2,3, XXV 3, XXVI 1.

2 Agradecemos la colaboración y amabilidad de D. RAFAEL VILA y especialmente la de D. JOSÉ MERINO MARTIN, «Polín», quien nos indicó la localización de los abrigos acompañándonos en numerosas excursiones.

${ }_{3}$ Se sitúa entre las coordenadas geográficas $1^{\circ} 39^{\prime} 40^{\prime \prime}-1^{\circ} 42^{\prime} 00^{\prime \prime}$ longitud OE y $38^{\circ} 40^{\prime} 40^{\prime \prime}-$ $38^{\circ} 40^{\prime} 30^{\prime \prime}$ latitud N. Hoja núm.806 (Cabeza del Buey) del Mapa Topográfico Nacional, escala 1:50000, Inst.Geográf. y Catastral, ed.1950.
} 
población que se localiza al pie de la vertiente meridional de la Sierra de Tiros. (Fig. 1). Esta sierra forma parte de la cadena montañosa que constituye el límite meridional de La Serena Oriental, planicie de pizarras paleozoicas en capas verticales, resistentes a la erosión y sin apenas suelo laborable, desprovista de vegetación arbórea y de matorral con características subesteparias, despoblada y destinada al pastoreo lanar principalmente ${ }^{4}$.

Los relieves que destacan en esta penillanura están constituidos fundamentalmente por cuarcitas silúricas, duras, de color predominantemente claro, con manchas rojas que produce el óxido de hierro, y posición vertical o muy próxima a ella. A sus pies y en sus laderas se extienden frecuentemente rañas de guijarrales cuarcíticos de cantos bastante rodados y de tamaño uniforme, que proceden de la denudación de las crestas cuarcíticas.

Son zonas en las que se da una vegetación mediterránea de monte bajo, con retamas, jaras, enebros, tomillo, lentisco,etc. y con algunas encinas, alcornoques, madroños, quejigo, y coníferas y eucaliptos en las zonas reforestadas. Cuando la densidad del encinar y el monte bajo se aclara se extienden dehesas de pastos y labor, siendo los principales cultivos de tipo herbáceo de secano, como la cebada y el trigo, olivos y algunas zonas de huerto. La ganadería es de tipo ovino, cabrío y porcino y todavía existe en las sierras caza mayor y menor.

El paisaje del pueblo de Helechal aparece dominado por dos cerros, La Morisca $(881 \mathrm{~m})$ y El Montón $(862 \mathrm{~m})$, y entre ambos se encuentra el Puerto de la Rueda, zona menos elevada y de paso al Valle de Navacerrada, que se abre al norte de éstos y que queda cerrado por relieves accidentados, siendo el Monte de Tiros (957 m) (T.M. Cabeza del Buey) el que presenta mayor altura.

De este valle toma su nombre el Arroyo de Navacerrada que discurre entre las faldas de ambos cerros. En la orilla oriental del arroyo y al pie de la vertiente occidental de La Morisca, se localizan una serie de charcas formadas por pequeños cursos de agua que en la actualidad se secan en verano pero que hasta hace pocos años mantenían su caudal constante. Esta zona es conocida por los habitantes de Helechal como Las Calderas y es precisamente en ella donde se encuentran tres de los yacimientos rupestres objeto de nuestro estudio. En el cerro de Las Moriscas se ubican, además de los dos ya publicados por Breuil, otros siete abrigos inéditos y

4 Hernández Pacheco, E., Fisiografía del Solar Hispano, Madrid, 1956, pp. 373-374. 
MAPA DE SITUACION GEOGRAFICA DE LOS ABRIGOS DE HELECHAL

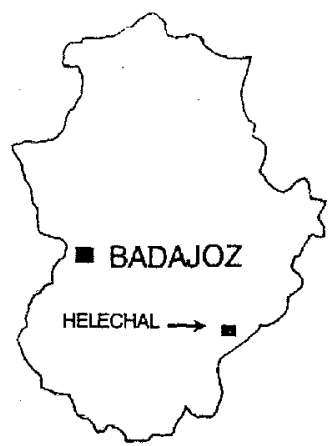

EXTREMADURA
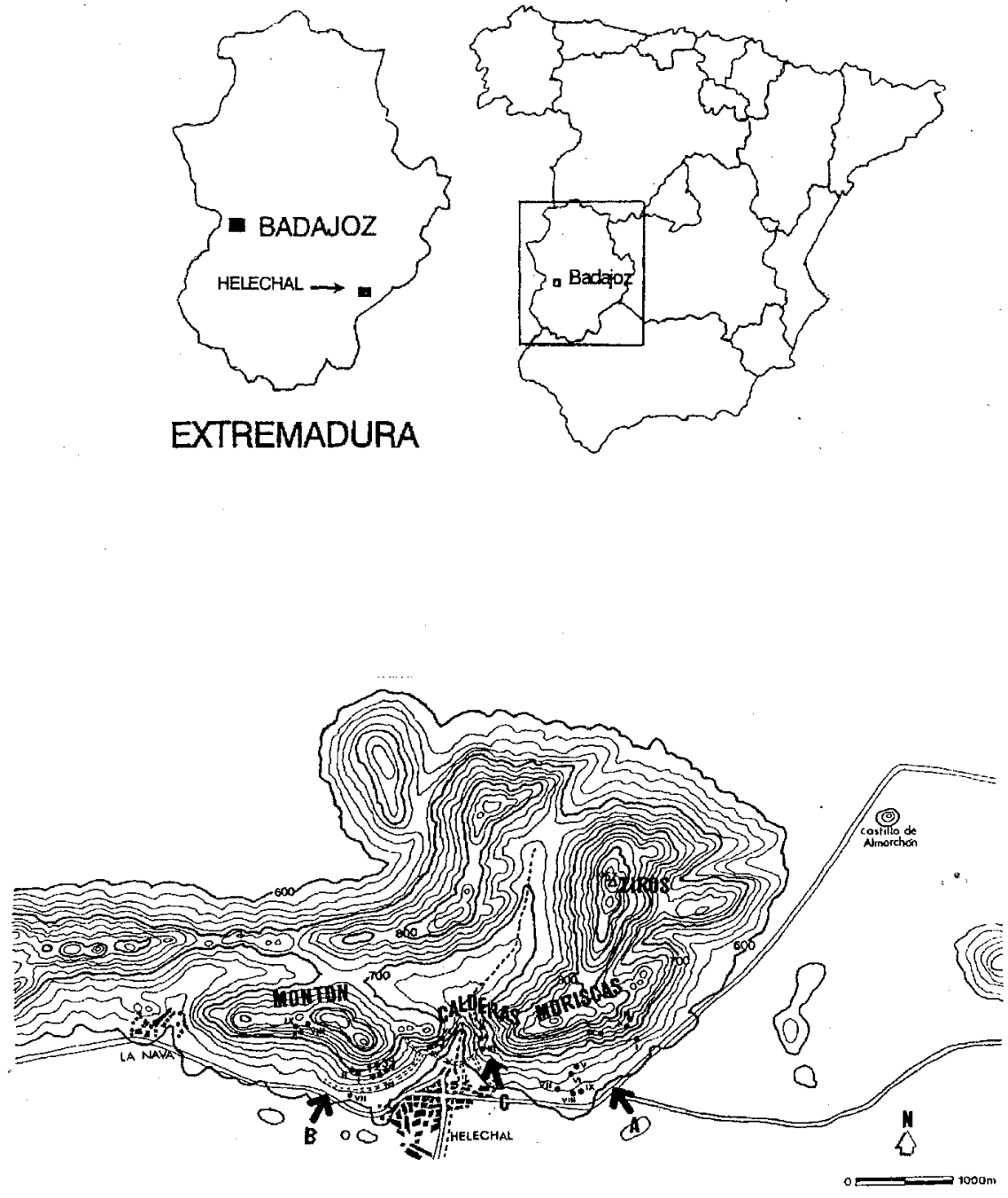

Figura 1. Situación de los abrigos de Helechal: A: Moriscas I a IX. B: Montón I a X. C: Calderas I a III. 
en El Montón hemos constatado la existencia de al menos diez nuevas estaciones que añadir a las estudiadas por el investigador francés, conocidas como Rocas $1^{\underline{a}}$ y $2^{\underline{a}}$ del Puerto de las Ruedas, Callejón del Peñón de Las Grajas y Peñón Amarillo del Olivar de las Grajas ${ }^{5}$.

Con estos nuevos descubrimientos son 23 las estaciones rupestres con pintura esquemática en Helechal, cuya importancia como centro de arte rupestre postpaleolítico resulta así innegable.

En el presente trabajo nuestro objetivo es dar a conocer tan importante conjunto artístico, dejando para posteriores ocasiones el análisis detallado de todos y cada uno de los motivos representados. Es por ello, y por el gran número de abrigos decorados, por lo que abreviaremos su descripción y la de las pinturas que en ellos encontramos.

\section{DESCRIPCIÓN DE LOS ABRIGOS}

Con el fin de facilitar la denominación de las estaciones rupestres hemos procedido a enumerarlas, incluyendo en esta numeración los abrigos ya estudiados por Breuil ${ }^{6}$, cuyo análisis obviamos.

\section{Cerro de Las Moriscas}

Para acceder a los nuevos abrigos partimos de los dos ya conocidos Abrigo del Zarzal y Abrigo Superior (Abrigos I y II) ${ }^{7}$. Son los primeros que se adelantan en el cerro al comenzar los escarpes y son de fácil identíficación.

5 BReUIL, H. Les peintures..., cit.,págs. 94-98, fig.31 y pl.X 5, XIX II, XXVII 2, X 3 y 4. La pl.XIX II que refleja el calco del segundo abrigo del Puerto de Las Ruedas aparece mal citada en el texto como pl.XIX $3^{\text {a }}$ y en el calco como perteneciente al T.M. de Peñalsordo, cuando en realidad pertenece a Helechal y al T.M. de Benquerencia. Los habitantes de Helechal sitúan el Puerto de Las Ruedas entre Las Moriscas y El Montón y no en el lugar que señala Breuil, separando El Montón y el cerro de Las Grajas, desconocido este último por los lugareños que lo consideran como una prolongación de El Montón.

6 Los abrigos publicados por BREull son denominados de nuevo con el fin de homogeneizar la nomenclatura empleada en todos los abrigos de la sierra: Las Moriscas: Abrigo del Zarzal (Abrigo 1), Abrigo Superior (abrigo II). El Montón: Roca 1a del Puerto de Las Ruedas (Abrigo VI), Roca $2^{\mathrm{a}}$ del Puerto de Las Ruedas (Abrigo XI), Callejón de las Grajas (Abrigo VIII) y Peñón Amarillo (Abrigo $X$ ).

7 Un reciente artículo ofrece nuevamente los contenidos pictóricos de estos abrigos, sin aportar novedades a lo ya publicado por el abate Breuil. Ortiz Macias, M. y Muñoz Torrero Caballero, E. (1994): Pinturas rupestres esquemáticas en la sierra de "Las Moriscas" (Helechal, Badajoz). Revista de Estudios Extremeños, vol.L, n II (mayo-agosto), págs. 267-280. 
Abrigo III

Altitud: $750 \mathrm{~m}$. Orientación: $160^{\circ} \mathrm{SE}$.

Acceso: situado a unos metros sobre el Abrigo II, siguiendo el carril abierto para el coto en dirección $\mathrm{N}$.

Descripción: Pequeño abrigo en el lateral derecho de un macizo rocoso, con una pared vertical de $3 \mathrm{~m}$ de alto y $1,20 \mathrm{~m}$ de ancho, afectada por líquenes y enrojecida por exudaciones de óxido férrico. Las pinturas se ubican en la mitad inferior de dicho lienzo rocoso.

Abrigo IV

Altitud: $750 \mathrm{~m}$. Orientación: $150^{\circ}$ SE.

Acceso: situado a unos $140 \mathrm{~m}$ del anterior en dirección S.

Descripción: Abrigo de $15 \mathrm{~m}$ de largo y $4 \mathrm{~m}$ de alto. Amplia visibilidad, pues desde él se contempla todo el valle. Presenta un único panel liso, sin líquenes y con la coloración típica rojiza, sobre el que se encuentran las pinturas.

Abrigo $V$

Altitud: $648 \mathrm{~m}$. Orientación: $190^{\circ} \mathrm{S}-\mathrm{SOE}$.

Acceso: Siguiendo el carril por el que se accede a los abrigos anteriores y bordeando el macizo rocoso en dirección $S$ una vez que el camino finaliza.

Descripción: Pared vertical, lisa y algo agrietada, exfoliada y con abundantes colonias de líquenes. Presenta unos $15 \mathrm{~m}$ de largo y $5 \mathrm{~m}$ de alto. Las pinturas se ubican en la mitad derecha del abrigo y en el panel central, ocupando una superficie de $4 \mathrm{~m}$ de ancho. Para acceder a ellas es necesario subirse a una plataforma rocosa de $1 \mathrm{~m}$ de altura.

Abrigo $\mathrm{Vl}$

Altitud: $640 \mathrm{~m}$. Orientación: $185^{\circ} \mathrm{S}-\mathrm{SOE}$.

Acceso: Descendiendo unos metros en dirección $S$ se llega à este nuevo abrigo.

Descripción: Abrigo de paredes lisas pero agrietadas, cuarteadas e irregulares en algunas zonas. Sus dimensiones son $5,60 \mathrm{~m}$ de largo y 5 $\mathrm{m}$ de alto. El friso con representaciones artísticas ocupa únicamente la 
zona central del abrigo, de 2,70 $\mathrm{m}$. de largo, y se halla afectado por los líquenes.

Abrigo VII o Cuevecilla

Altitud: $620 \mathrm{~m}$. Orientación: $180^{\circ} \mathrm{S}$.

Acceso: Abandonando el macizo rocoso sobre el que se sitúan los abrigos $\mathrm{V}$ y VI, se desciende por los escarpes en dirección $\mathrm{S}$ hasta esta nueva estación rupestre.

Descripción: Se trata de una pequeña cuevecilla u oquedad en la roca con forma triangular, en cuyo interior, de superficie muy irregular, con numerosos entrantes y salientes y afectada por líquenes, se disponen las pinturas tanto en la pared de la derecha como en el techo, situado a unos $50 \mathrm{~cm}$ de la base. Esta mantiene una inclinación de unos $45^{\circ}$. Desde allí se contempla un amplísimo paisaje, dominando todo el valle.

\section{Abrigo VIII}

Altitud: $600 \mathrm{~m}$. Orientación: $170^{\circ} \mathrm{S}$-SE.

Acceso: Dejando atrás la Cuevecilla, marchando unos metros hacia el $E$, en la segunda pared vertical que encontramos se sitúa esta estación rupestre.

Descripción: Es una pared vertical de unos $8 \mathrm{~m}$ de altura, cubierta de líquenes y con un único y pequeño panel liso, rojizo, en su mitad izquierda. En él se representa solamente un motivo esquemático.

\section{Abrigo IX}

\section{Altitud: $590 \mathrm{~m}$. Orientación: $175^{\circ} \mathrm{S}$-SE.}

Acceso: Caminando unos $30 \mathrm{~m}$ en dirección $\mathrm{E}$ se accede a este abrigo IX.

Descripción: Se trata de un abrigo formado por una pared vertical sobre una plataforma rocosa de unos $2 \mathrm{~m}$ de altura.

Sus dimensiones son $7,40 \mathrm{~m}$ de largo y unos $2,5 \mathrm{~m}$ de alto. Se encuentra casi totalmente cubierto por formaciones de líquenes y sus paredes son muy irregulares, exceptuando los paneles de la derecha del abrigo, lugar en el que la roca muestra un recodo. Es precisamente en este lugar en el que, en un espacio de 1,10 m de largo, se desarrollan las pinturas esquemáticas, dibujadas sobre un lienzo liso libre de líquenes y enrojecido por el óxido de hierro. 
Cerro El Monton

Abrigo I

Altitud: $700 \mathrm{~m}$. Orientación: $70^{\circ} \mathrm{NE}$.

Acceso: Partiendo del extremo septentrional del pueblo, al pie de Las Moriscas, y siguiendo un corto trayecto por una vereda, se llega al ancho carril realizado para el coto. Caminando por éste hasta que termina y bordeando después la sierra en dirección $\mathrm{S}$ se accede a una serie de abrigos, situados frente al recodo que hace la carretera general antes de entrar en el centro urbano de Helechal. Uno de ellos es el que aquí presentamos.

Descripción: Se trata de un abrigo formado por dos grandes lajas de piedra paralelas en su disposición vertical y convergentes en la horizontal, ligeramente inclinadas al $\mathrm{N}$. Forman un estrecho callejón o corredor de unos $8,5 \mathrm{~m}$ de largo, unos $12 \mathrm{~m}$ de alto y una anchura máxima de $1 \mathrm{~m}$. Desde su entrada se contempla un amplio panorama: la Sierra de Tiros, Las Moriscas, la zona norte de Helechal, el Puerto de Las Ruedas y el valle sobre el que se asienta el pueblo.

Las pinturas se encuentran en la pared de la izquierda, situándonos frente a la boca del abrigo. Se trata de un lienzo liso pero afectado por. grietas y exfoliaciones, concreciones, exudaciones de óxido férrico, colonias de líquenes y ennegrecimiento provocado por el humo de hogueras. Todo ello afecta mucho a la conservación de las pinturas y a su visibilidad.

\section{Abrigo II}

Altitud: $690 \mathrm{~m}$. Orientación: $150^{\circ} \mathrm{SE}$.

Acceso: Descendiendo unos metros del anterior y marchando en dirección N.

Descripción: Se trata de un abrigo cuyo exterior presenta una forma triangular y unos $6 \mathrm{~m}$ de altura y en cuyo interior, sobre la pared lateral de la izquierda y a 2,40 $\mathrm{m}$ del suelo, aparecen unas pinturas esquemáticas, bastante protegidas de las inclemencias atmosféricas y por ello muy bien conservadas. El abrigo ofrece una anchura de unos $4 \mathrm{~m}$ y la zona más horadada y protegida una altura de $2 \mathrm{~m}$. Aproximadamente a $5 \mathrm{~m}$ a la derecha del abrigo, sobre la pared rocosa, se plasman de nuevo algunos motivos esquemáticos. 
Abrigo III

Consideramos como Abrigo III a un conjunto de cuatro abrigos muy próximos e indudablemente relacionados, dado lo muy difícil de su acceso.

Para llegar a ellos se debe tomar el carril del coto que se dirige al Puerto de La Rueda. Una vez alcanzados los primeros peñascos del Montón se asciende por los escarpes de la ladera hasta encontrar una gran pared vertical que presenta dos lajas de piedra dispuestas de tal modo que dejan un estrechísimo paso. Entrando por éste y bordeando el macizo rocoso de muy difícil transitabilidad, pues es menester escalar por los escarpes a cuyos pies se abre un barranco, se accede a una plataforma horizontal en la que se disponen uno tras otro varios abrigos. En cuatro de ellos se observan pinturas rupestres esquemáticas. Todos ellos ofrecen una amplia visibilidad dominando el Puerto de La Rueda, Las Moriscas, el valle y Helechal. Comenzamos la descripción por el más alejado, el más meridional.

\section{Abrigo III.1}

Altitud: $660 \mathrm{~m}$. Orientación: $100^{\circ} \mathrm{E}$.

Descripción: Abrigo constituido por una pared vertical de unos 15 $\mathrm{m}$ de altura, muy irregular y fracturada con grandes diaclasas, afectada por el óxido férrico y los líquenes. Protege una terraza horizontal de tierra muy suelta, de $8 \mathrm{~m}$ de largo y $9 \mathrm{~m}$ de ancho aproximadamente, que limita con el barranco. Las pinturas se representan en un único panel, en el interior de una oquedad que se abre en la pared y en la que se observa una especie de muro natural que forma un espacio que pudo haberse empleado como silo o contenedor.

Abrigo III.2

Altitud: $666 \mathrm{~m}$. Orientación: $110^{\circ} \mathrm{E}$.

Descripción: Se trata de nuevo de un abrigo con una plataforma a sus pies, de unos $9 \mathrm{~m}$ de largo y $7 \mathrm{~m}$ de ancho.

La pared vertical que lo constituye ofrece $25 \mathrm{~m}$ de altura aproximada y su superficie es bastante lisa, algo agrietada, y de aspecto rojizo excepto en las zonas sobre las que se han formado líquenes, que se mantienen blancas. 
Abrigo III.3

Altitud: $675 \mathrm{~m}$. Orientación: $135^{\circ} \mathrm{SE}$.

Descripción: Abrigo profundo, ofrece un espacio interior recogido por lo erosionado de su base y lo pronunciado de su visera, de la que se ha desprendido un peñón que cierra la entrada. La pared vertical está bastante cuarteada y absolutamente cubierta de musgos y líquenes. Solo es liso el interior del abrigo, el techo, sobre el que se dibujan las figuras esquemáticas. La terraza del abrigo es horizontal y transitable. Tiene $12 \mathrm{~m}$ de largo y $5 \mathrm{~m}$ de ancho.

Abrigo III.4

Altitud: $677 \mathrm{~m}$. Orientación: $150^{\circ} \mathrm{SE}$.

Descripción: Nos encontramos ante el mayor de estos abrigos. Formado por paredes verticales bastante lisas y con marcados entrantes y salientes, coronado por los restos de lo que debió ser una gran visera, hoy derrumbada a juzgar por los enormes bloques de piedra que cubren gran parte de la terraza o plataforma. Esta debió tener unos $12 \mathrm{~m}$ de ancho, pero actualmente solo son transitables unos $5 \mathrm{~m}$, puesto que el resto aparece cubierto por las grandes piedras mencionadas. Lo más probable es que en la época en que fueron realizadas las pinturas ya existiera este derrumbe, a tenor de la altura a la que fueron plasmados los motivos sobre las paredes. El lienzo rocoso aparece muy afectado por exudaciones férricas, líquenes y exfoliaciones, mostrando la roca una coloración rojiza y negruzca que dificulta mucho la visión de las pictografías. Hemos diferenciado cuatro paneles pintados en este abrigo, separados entre si y, dada la irregularidad de las paredes, con distintas orientaciones.

Abrigo IV

Altitud: $650 \mathrm{~m}$. Orientación: $65^{\circ} \mathrm{NE}$.

Acceso: Situándonos nuevamente en el cruce del carril del coto y el camino que parte a su izquierda y bordea El Montón, se observan en la ladera SE del cerro una serie de abrigos. El primero de ellos es el aquí descrito.

Descripción: Se trata de una abrigo con forma de pequeño covacho poco profundo, apenas $1,5 \mathrm{~m}$, de forma semicircular y cerrado por un murete artificial de piedras. Sus paredes son irregulares y aparecen ennegrecidas por el humo - restos de una hoguera evidencian su continuidad como refugio de pastores-, enrojecidas por el óxido férrico y cubiertas 
en algunas zonas por líquenes y nidos de vencejos. Una única pintura se sitúa sobre la pared del fondo del abrigo.

Abrigo $\mathrm{V}$

Altitud: $655 \mathrm{~m}$. Orientación: $65^{\circ} \mathrm{NE}$.

Acceso: Caminando unos $15 \mathrm{~m}$ a la derecha del abrigo anterior.

Descripción: Se trata de un abrigo constituido por paredes verticales, de unos $22 \mathrm{~m}$ de largo y $10 \mathrm{~m}$ de alto, dividido en dos por una gran fisura vertical. Los paneles pintados se disponen en la mitad izquierda y están muy afectados por el ennegrecimiento provocado por el humo de hogueras y por las colonias de líquenes, que cubren cași totalmente las pinturas.

\section{Abrigo VII}

Altitud: $610 \mathrm{~m}$. Orientación: $320^{\circ}$ NOE.

Acceso: Tomando nuevamente el carril del coto y siguiendo el camino de la izquierda se pasa por un estrecho pasadizo formado por dos grandes paredes verticales. En una de ellas se sitúan varios motivos esquemáticos.

Descripción: Este pasadizo presenta una longitud de $24,5 \mathrm{~m}$ y una anchura de $3,90 \mathrm{~m}$. Las paredes que lo constituyen tienen una altura de 10 $\mathrm{m}$ aproximadamente. Las pinturas se disponen sobre la pared más meridional, por lo que el lienzo queda orientado al NOE. Debió contener abundantes representaciones artísticas dada la idoneidad que presenta para ello, pero los líquenes cubren casi totalmente la roca. A pesar de ésto y de las pintadas modernas que también afectan al panel, se pueden observar todavía algunos motivos a más de $2 \mathrm{~m}$ del suelo actual, bastante rebajado con respecto al antiguo al hacerse el camino.

Abrigo IX

Altitud: $770 \mathrm{~m}$. Orientación: $185^{\circ}$ SOE.

Acceso: Situado en la vertiente SOE del Montón ${ }^{8}$, fue denominada por Breuil Cerro de Las Grajas. Ascendiendo por esta vertiente encontramos

s Esta vertiente de EI Montón fue tomada por BREUIL como un cerro independiente y lo denominó Las Grajas. Este apelativo hoy es desconocido por los habitantes de Helechal y no figura en el Mapa Topográfico ya indicado. 
un primer risco que hay que bordear en dirección OE. Frente a este se localiza una pared rocosa a la que hay que subirse para llegar a este abrigo.

Descripción: Se trata de un abrigo de muy pequeñas dimensiones, casi $1 \mathrm{~m}$ de profundidad y de anchura máxima en la entrada, formado al horadarse la base de la roca y con un gran peñón ante él. En el interior, a la izquierda, sobre la superficie irregular del techo, se dibuja un único motivo a $61 \mathrm{~cm}$ del suelo.

\section{Las Calderas}

Partiendo del límite septentrional de Helechal hacia el valle que se abre entre Las Moriscas y El Montón, por el que circula el Arroyo de Navacerrada, existe una vaguada en la que entre riscos, peñascos y charcas secas encontramos varias estaciones rupestres.

\section{Abrigo 1}

Altitud: $660 \mathrm{~m}$. Orientación: $325^{\circ}$ NOE.

Acceso: Una de estas charcas mencionadas está formada por dos grandes paredes de piedra dispuestas de tal modo que forman un estrecho pasillo orientado $95^{\circ}$ al $\mathrm{E}$ y cubiertas por un enorme peñasco. Este callejón quedaba inundado por el arroyo que discurría por su cauce y formaba una charca bastante profunda. Al fondo, un peñón no quedaba cubierto por el agua al hallarse situado unos metros por encima de su nivel, formando en esta zona una pequeña cascada. En una de las paredes de este peñón se sitúan las pinturas rupestres.

Descripción: El lienzo pintado ocupa una superficie unos $2 \mathrm{~m}$ de longitud y se halla muy afectado por líquenes y exudaciones de óxido férrico. Se distinguen dos paneles, de izquierda a derecha, separados por unos 90 $\mathrm{cm}$. El primero dispuesto a $1,50 \mathrm{~m}$ del suelo y el segundo a $80 \mathrm{~cm}$.

\section{Abrigo II}

Altitud: $680 \mathrm{~m}$. Orientación: $20^{\circ} \mathrm{NE}$.

Acceso: Partiendo del abrigo anterior en dirección al pueblo, sobre unos peñascos situados frente a nosotros, antes de deslizarnos por una rampa lisa por la que hay que descender, existe una grieta formada por varios peñones que han caído. Al introducirnos por ella se accede a un pequeño espacio cobijado por las rocas, orientado $270^{\circ}$ al OE. 
Descripción: En una de las enormes piedras caídas que lo forman, indudablemente fuera de su emplazamiento original, se halla la pintura de un motivo esquemático. Esta se sitúa sobre la base inclinada del peñón, que debió constituir la pared vertical de algún abrigo y que presenta una longitud de 2,50 m. La figura aparece boca abajo.

\section{Abrigo III}

\section{Altitud: $660 \mathrm{~m}$. Orientación: $70^{\circ} \mathrm{NE}$.}

Acceso: Siguiendo el camino que parte del pueblo y que discurre paralelo al arroyo se accede al carril del coto en sus inicios. A su derecha aparecen unos primeros peñascos en los que se sitúa este abrigo.

Descripción: Se trata de una piedra de enormes dimensiones que también se encuentra desplazada de su lugar original, unos metros más arriba, pues todavía queda la marca de su antiguo emplazamiento. Sobre uno de sus lados se observan restos de pintura, dispuestos a medio metro del suelo actual, muy afectados por los líquenes e inclinados con respecto a su posición primitiva.

\section{LAS PINTURAS RUPESTRES}

Con el fin de sintetizar en lo posible, hemos optado por presentar una descripción de las pinturas en general, reflejando los diferentes tipos de motivos que encontramos ${ }^{9}$, la frecuencia de su representación, los colores que conservan ${ }^{10}$, las dimensiones de las figuras ${ }^{11}$, las asociaciones existentes entre ellas, las superposiciones y su estado de conservación.

\section{Consideraciones tipológicas:}

Conviene resaltar una serie de cuestiones tipológicas, que nos aportan interesantes datos. En primer lugar, nos encontramos ante un conjunto

- Para la tipología hemos seguido en parte la clasificación de PILAR ACOSTA en «La pintura rupestre esquemática en España", Salamanca, 1968.

10 Para la identificación del color hemos empleado la tabla cromática Pantone Color Formula Guide, 5th Printing, 1988-89, Pantone Inc. New Jersey, USA. Los colores se tomaron en primavera y otoño, a mediodía y con el soporte húmedo. La época del año, las condiciones ambientales de humedad y luz, el estado del soporte y del pigmento, etc., son factores que determinan sin duda el color que muestran en la actualidad los motivos, por lo que creemos que su análisis no resulta muy significativo. De cualquier modo, un estudio exahustivo de las pinturas requiere detenerse en este aspecto por lo que no lo desdeñamos.

11 Las dimensiones de las figuras se expresan en altura y anchura máxima. 
que contiene en su totalidad 622 figuras ${ }^{12}$, lo que le otorga una indudable importancia como centro de arte rupestre. Decimos conjunto pues así es como debemos considerarlo, no solo por la proximidad física de los abrigos que contienen estas manifestaciones pictóricas, sino también por las numerosas características comunes que éstas presentan.

De estos motivos, 378 se plasman en El Montón, 200 en Las Moriscas y 44 en Las Calderas.

Todos ellos están realizados con un estilo netamente esquemático, y su alto nivel de abstracción dificulta enormemente su interpretación.

El motivo más frecuentemente representado es el de las barras, que aparece en 261 ocasiones en los abrigos I, III.2,3 y 4, y V de El Montón, 56 veces en los abrigos III, IV, V, VII y IX de Las Moriscas y 24 veces en al abrigo I de Las Calderas.

Este es, además, el tipo más repetido en los abrigos de la zona oriental de La Serena ${ }^{13}$ y en la mayoría de las estaciones rupestres de la Península Ibérica. Algunos de los yacimientos rupestres más próximos que contienen barras son los abrigos I al $\mathrm{X}$ de Los Buitres (Capilla) ${ }^{14}$, el Abrigo de la Cruz Chiquita (Peñalsordo) ${ }^{15}$, el Cerro Estanislao, los abrigos de la Sierra de Las Cabras o de Puerto Alonzo y el Abrigo del Peñón Amarillo del Callejón del Valle del Aliso (Cabeza del Buey) ${ }^{16}$.

Lo más general es su dibujo en vertical y en conjuntos de dos o más elementos (hasta 14 en un panel del abrigo Montón III.4), probablemente con un carácter enumerativo, de incipiente sistema de cuentas. Aunque no podemos asegurar el material que de este modo se contabiliza podría tratarse de seres humanos en muchos casos, pues es posible distinguir en algunas barras formas que podrían corresponder a sus siluetas. Sin embargo también se constata su asociación con círculos, con puntos o digitaciones, con esteliformes y soliformes, con tectiformes, con ramiformes y con pectiniforme en los abrigos de El Montón, mientras que en Las Moriscas se añade la asociación barra-ciervo.

La interpretación de estas asociaciones resulta complicada, aunque en algunos casos podemos aventurar algunas hipótesis. Así en el caso de la

12 Excluimos en estos análisis los abrigos próximos ya estudiados por BREUIL.

13 Martinez Perelló, M.I. (1993): La pintura rupestre esquemática en la zona oriental de la provincia de Badajoz, Espacio, Tiempo y Forma, Serie I, t.6, pág. 109.

14 BreUlL, Les peintures...cit., vol.II, págs. 42-65, figs.14-20, PI.XIII-XX y XXXVII.

15 Martínez Perelló, Un nuevo conjunto de pinturas..., cit., pág. 201, fig. 9.

16 BreuIL, Les peintures..., cit., vol.II, PI.XXIII:B, PI.XXIV:IV y VII. 
asociación barras-soliforme que se dibuja en el abrigo Montón III.4 (Fig. 2) podría tratarse de un pequeño grupo humano, familiar o tribal, puesto por los artistas en relación con una representación astral, lo que les otorgaría un carácter especial dentro de su propia comunidad.
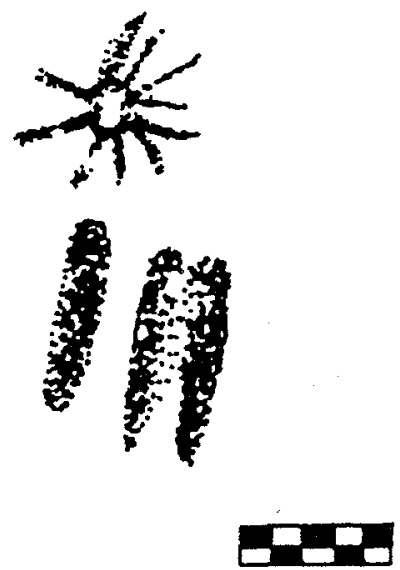

Figura 2. Montón III.4. Detalle.

Es interesante también la asociación barras-tectiforme que se plasma en el abrigo Montón 111.3 (Fig. 3). En ella, una figura reticular de color blanco se representa sobre tres barras rojas, tal vez con la intención de expresar algún tipo de vivienda o estructura que cobijaría a tres figuras humanas.
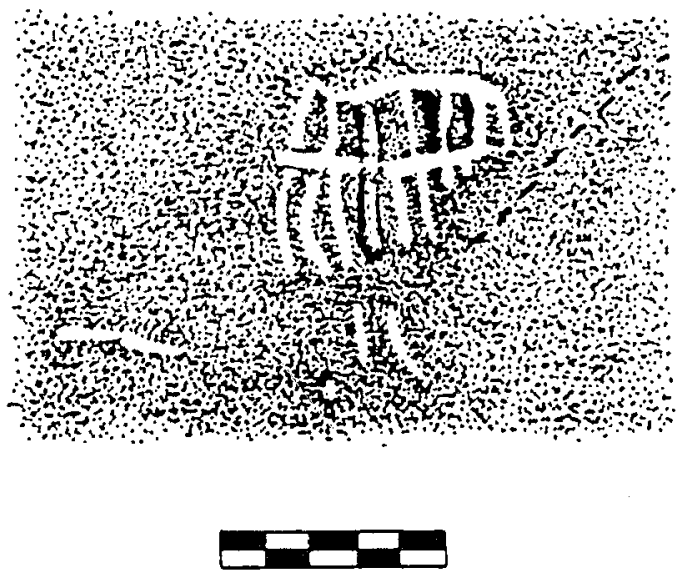

Figura 3. Montón III.3. Detalle. 
Finalmente, la asociación barra-ciervo que aparece en el abrigo Moriscas IV (Fig. 4) tal vez podríamos interpretarla como una representación del suelo sobre el que se situaría el pequeño cérvido, algo poco frecuente en la pintura rupestre esquemática peninsular.

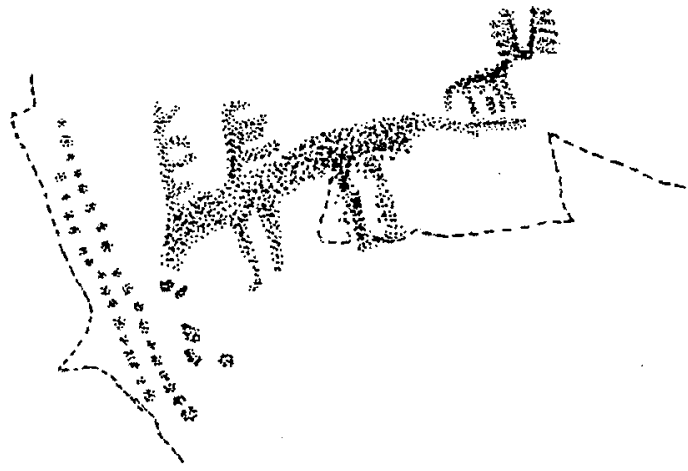

Figura 4. Moriscas IV. Detalle.

El segundo tema más representado es el de los puntos. Aparece 31 veces en los abrigos III.1, III.4 y VII de El Montón, en 106 ocasiones en los abrigos II, IV, $\mathrm{V}$ y IX de Las Moriscas, y 8 veces en el Abrigo I de Las Calderas.

Se asocia con barras o con otros puntos formando conjuntos lineales.

Conjuntos similares hallamos en los abrigos II, V, y VIII de Los Buitres ${ }^{17}$, en el Abrigo del Morro del Valle de la Venta (Cabeza del Buey) ${ }^{18}, \mathrm{Pez}$ I y Abrigo del Castillo de Capilla (Capilla) ${ }^{19}$ y Cerro Estanislao (Cabeza del Buey) ${ }^{20}$. En el Abrigo IV de Las Moriscas se asocia además con una figura de cérvido (Fig. 4), y en otras estáciones rupestres lo hace con círculos y con figuras soliformes disponiéndose como punto central o como agrupación de varios puntos en su interior, como vemos en Moriscas V (Fig. 5).

17 BREUIL, Les peintures..., cit., vol. II, PI. XV:C y B y PI. XVII:A.

18 Martinez Perelló, M.I. (1993): Arte Rupestre en Badajoz. Un nuevo abrigo con pinturas esquemáticas: el morro del Valle de la Venta (Cabeza del Buey). Revista de Estudios Extremeños, $\mathrm{T}$. XLIX, núm II (mayo-agosto), págs. 312 y 321 , figs. 5 y 6.

19 Martínez Perelló, Un nuevo conjunto de pinturas..., cit., pág. 211 y fig. 9.

20 BreUIL, Les peintures..., cit., vol. II, PI. XXIII:B. 

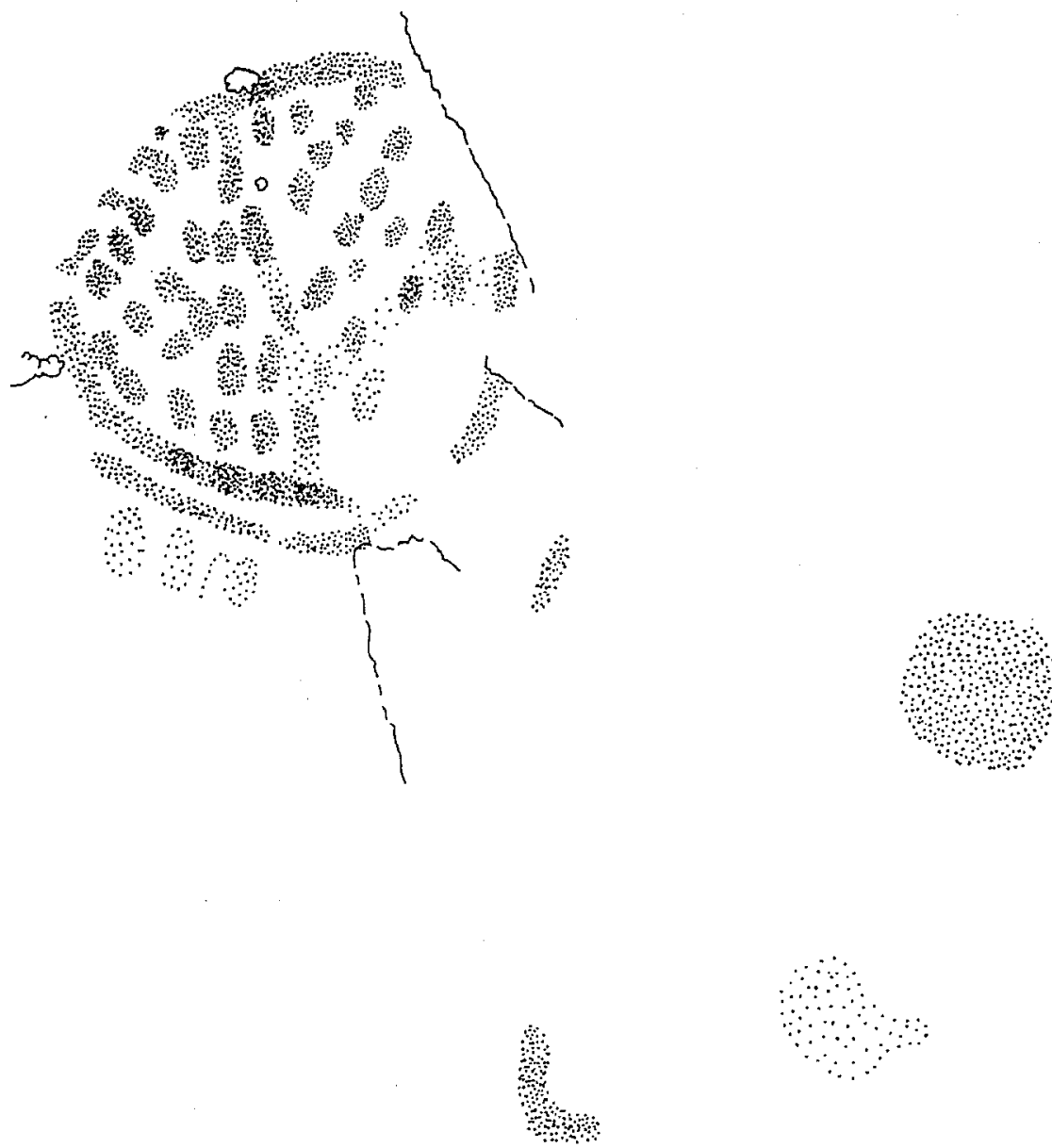

Figura 5. Moriscas V. Detalle. 
La figura del tipo ramiforme es especialmente abundante en Montón III.4, con 9 ejemplares. Los abrigos I, II, III.1 y IX también acogen estos motivos. Son en total 13 las representaciones que se contemplan en este cerro. En Las Moriscas no son tan numerosas, con 3 figuras en el Abrigo VIl, y en Las Calderas se observa un único motivo en el Abrigo III.

Las asociaciones ramiforme-bitriangular, ramiforme-barras, ramiforme«phi», y ramiforme-pectiniforme (Abrigo II Las Moriscas) (Fig. 6), ramiforme-puntos (Abrigo III.1 El Montón) (Fig. 7) y ramiforme-serpentiforme-soliforme (Abrigo III.4) (Fig. 8) son difíciles de interpretar. Pueden tratarse de abstracciones vegetales asociadas a zoomorfos (pectiniformes, serpentiformes), de esquematizaciones de astas de cérvidos, o de representaciones antropomorfas. A esta última interpretación parece aproximarse más el motivo de Montón III.4 asociado a un serpentiforme y a un soliforme diminuto.

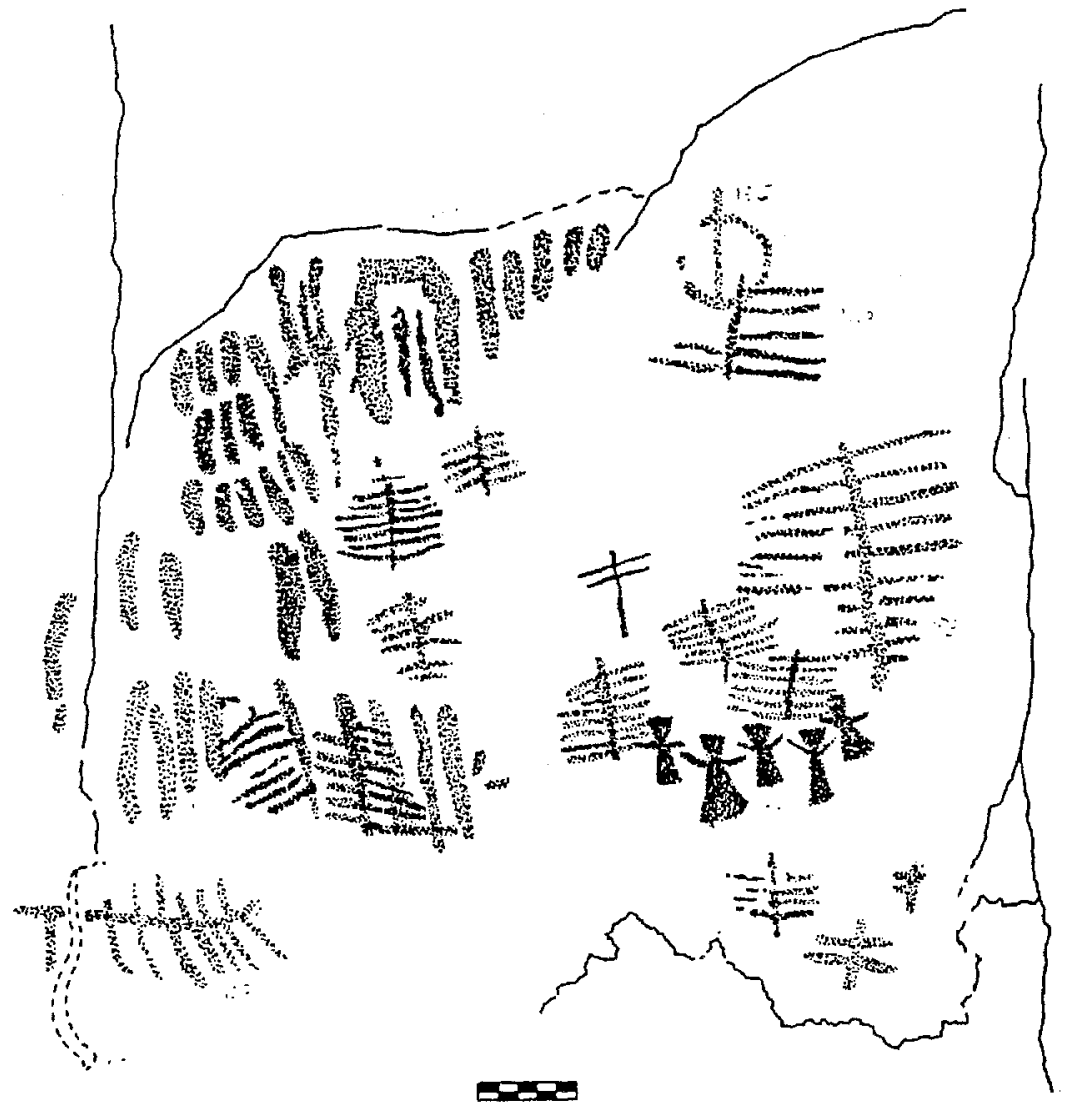

Figura 6. Moriscas II. Detalle. 


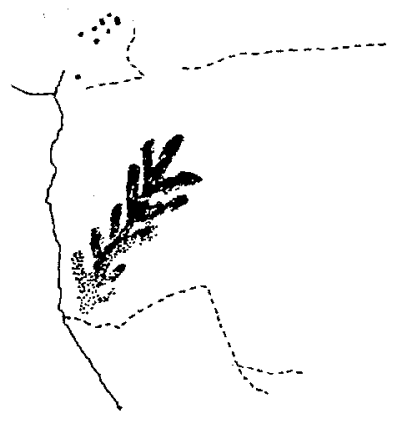

50

Figura 7. Montón III.1. Detalle.

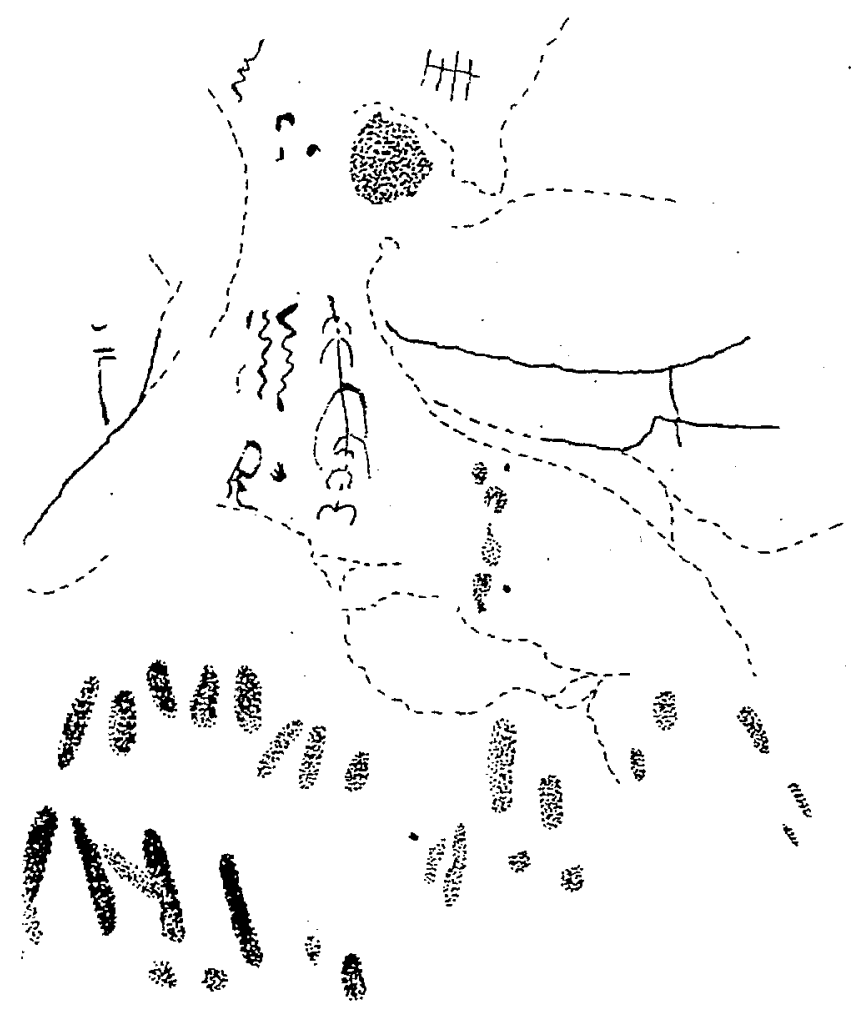

마몽

Figura 8. Montón III.4. Detalle. 
Figuras de tipo ramiforme encontramos en algunos abrigos muy próximos a Helechal, como son Los Buitres I, IV y VI, Peñón Amarillo, Puerto Alonzo, Pez I y IV, el Valle de la Huerta Vieja, el Morro del Valle de la Venta, Cueva del Bercialejo y Cueva Superior de la Fuente del Peral ${ }^{21}$.

Círculos, figuras del tipo «phi» griega, ancoriformes, esteliformes, soliformes y cruciformes son motivos que aparecen frecuentemente concentrados en determinados abrigos o en determinado cerro.

Las figuras en círculo, por ejemplo, aparecen dibujadas doce veces, únicamente en el Abrigo I de El Montón y todas sobre el mismo panel rocoso. Se representan tanto con el interior vacío como rellenas de puntos o con un único punto central. Es significativa su asociación, dada su proximidad, con figuras del tipo esteliforme, formadas por un círculo del que parten hacia arriba o hacia abajo varios trazos rectos y verticales y con figuras soliformes, en las que esos trazos se disponen radialmente. La alta concentración de 12 círculos, 6 esteliformes y 5 soliformes en el mismo abrigo, en el que también aparecen 96 barras, 1 ramiforme y 9 indeterminados, hace pensar en una dedicación específica de este lugar que podría tener un significado especial, mágico, ritual o conmemorativo (Fig. 9).

En el Abrigo $V$ de Las Moriscas se dibuja un extraño círculo de grandes dimensiones, $20 \times 20 \mathrm{~cm}$, en cuyo interior se sitúan hasta 36 puntos dispuestos de tal modo que constituyen una figura ramiforme. Observamos, por tanto, la asociación círculo-puntos, sin darse ninguna otra en este caso, ya que esta figura aparece aislada en el panel, con la única proximidad de cinco barras (Fig. 5). Encontramos también una figura circular con su interior relleno de puntos en el abrigo próximo de Los Buitres II ${ }^{22}$.

Las figuras en "phi» griega están formadas por un círculo atravesado verticalmente por una barra que en ocasiones sobresale por su extremo superior o inferior, y se dibujan principalmente en el lienzo rocoso que ofrece el Abrigo VI de Las Moriscas. Se contemplan en total 7 figuras, que se asocian a 3 representaciones muy similares atravesadas horizontalmente por otro trazo, que las aproxima morfológicamente a la representación esquemática de una rueda, tal y como encontramos formando carros en las pinturas rupestres de Buitres $V$ y $X$. Sin embargo, el que en alguna

21 BreUlL, Les peintures..., vol.II, PI.XV:B, fig.16, y PI.XIX:A, PI.XXIV:VII, PI.XXII:2.

Martinez Perelló, Un nuevo conjunto..., cit., págs. 201 y 209, fig.6, pág. 211 y fig 8.

Martinez Perelló, Arte rupestre en Badajoz..., cit. págs. 312, 316 y 320, figs. 3, 7, 8, 9, 10 y 11.

22 Breuil, Les peintures..., cit., vol.II, PI.XV:B. 


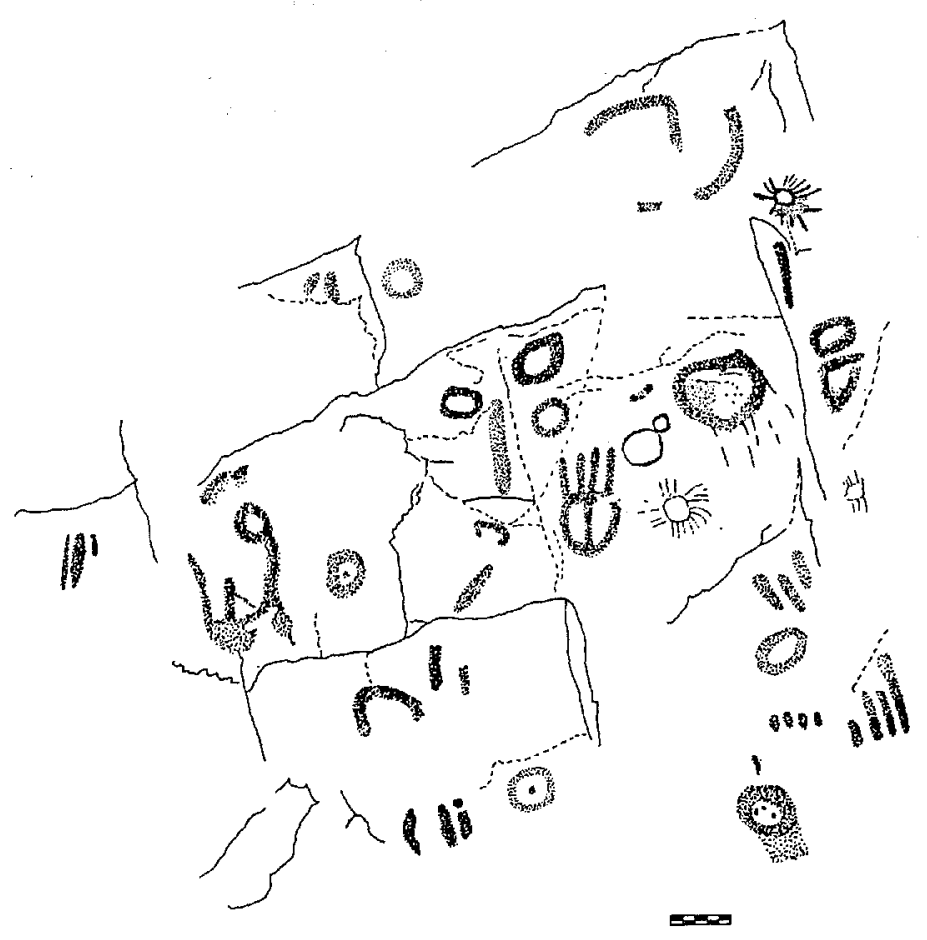

Figura 9. Montón 1. Detalle.

aparezcan dos puntos en su interior, otorgando a la figura un posible carácter oculado, y el que este tipo esté representado en los grabados al aire libre, hace que las consideramos como figuras petroglifoides.

Los abrigos IV, V, VII y IX contienen también cada uno un ejemplar de figura en "phi», considerada por algunos autores como figura antropomorfa de brazos en asá, lo que hace un total de 11 representaciones de este tipo concentradas en los abrigos de Las Moriscas. En Montón VII y X hallamos igualmente figuras en «phi». En el entorno próximo a todos estos yacimientos rupestres existen varios abrigos que contienen en sus paneles pinturas de este tipo: Buitres I, Hoya de la Huerta y Morro del Valle de la Venta ${ }^{23}$.

Los dibujos del tipo ancoriforme se localizan, en cambio, en los abrigos de El Montón. Aparecen 5 en el Abrigo V, 2 en el Abrigo VII y 1 en el IV

23 Martínez Perello, La pintura rupestre esquemática..., cit., pág. 112. 
como motivo único. También observamos algunos ejemplos en Moriscas II y VI. En sus proximidades encontramos este diseño en los abrigos de la Sierra de las Cabras y en la Cueva del Bercialejo ${ }^{24}$.

Hemos considerado como figura tipo golondrina una representación que aparece en Montón VII junto a los ancoriformes pero cuyo eje vertical sobresale unos milímetros por su extremo superior. Estas figuras se muestran aisladas, sin asociarse a figuras de otro tipo, pero sí se relacionan entre ellas. Motivos en golondrina se dibujan en Buitres I, Buitres X, Sierra de las Cabras, Castillo de Capilla, Pez I, Bercialejo y Pozo Retumba ${ }^{25}$.

Los esteliformes, que ya hemos descrito en el párrafo dedicado a los círculos, se circunscriben casi exclusivamente a los paneles pintados de Montón I, donde se representan 6 de estas figuras (Fig. 9).

Sin embargo también en el Abrigo III.4 del mismo cerro aparece un motivo de este tipo (Fig. 8).

Las líneas rectas y verticales que parten del trazo circular se dirigen tanto hacia arriba como hacia abajo, y el círculo ofrece varios aspectos: se rellena de puntos, se dibuja un único punto central, se atraviesa verticalmente por una línea central formando una figura híbrida entre el esteliforme y la figura en "phi», o sencillamente se deja vacío. En cuanto a su asociación con otros tipos de representaciones, encontramos las siguientes relaciones: esteliforme-barras, esteliforme-esteliforme, esteliforme-soliforme (Montón I), y esteliforme-ramiformes-serpentiformes (Montón III.4).

Los soliformes se diferencian de los anteriores por la disposición radial de los trazos rectos que parten del círculo, lo que les otorga un aspecto astral.

Al igual que las figuras esteliformes se concentran en Montón I (Fig. 9) y en Montón III.4 (Fig. 2), con una única representación. Motivos similares hallamos en los abrigos I y IX de Los Buitres, en este último caso con una pareja de ramiformes en su interior ${ }^{26}$.

Sin embargo, el Abrigo $V$ de Las Moriscas contiene 2 figuras de este tipo asociadas a una figura antropomorfa de tipo cruciforme. Estos soliformes se sitúan a ambos lados de la cabeza de la representación humana, uno con su espacio interior vacío y el otro con un punto central,

24 Martínez Perelló, La pintura rupestre..., cit., pág. 111.

25 Martínez Perelló, La pintura rupestre esquemática..., cit., pág. 110.

26 Breull, Les peintures..., cit., vol.II, págs. 58-59, PI.XIX VC, fig. $16 \mathrm{f}$. 
dotando a la figura de un carácter especial que permite que la consideremos como una representación de ídolo de tipo oculado (Fig. 10).

Los motivos de tipo cruciforme se dibujan en 7 ocasiones y principalmente en Las Calderas. En Calderas I encontramos 5 figuras (Fig. 11) y
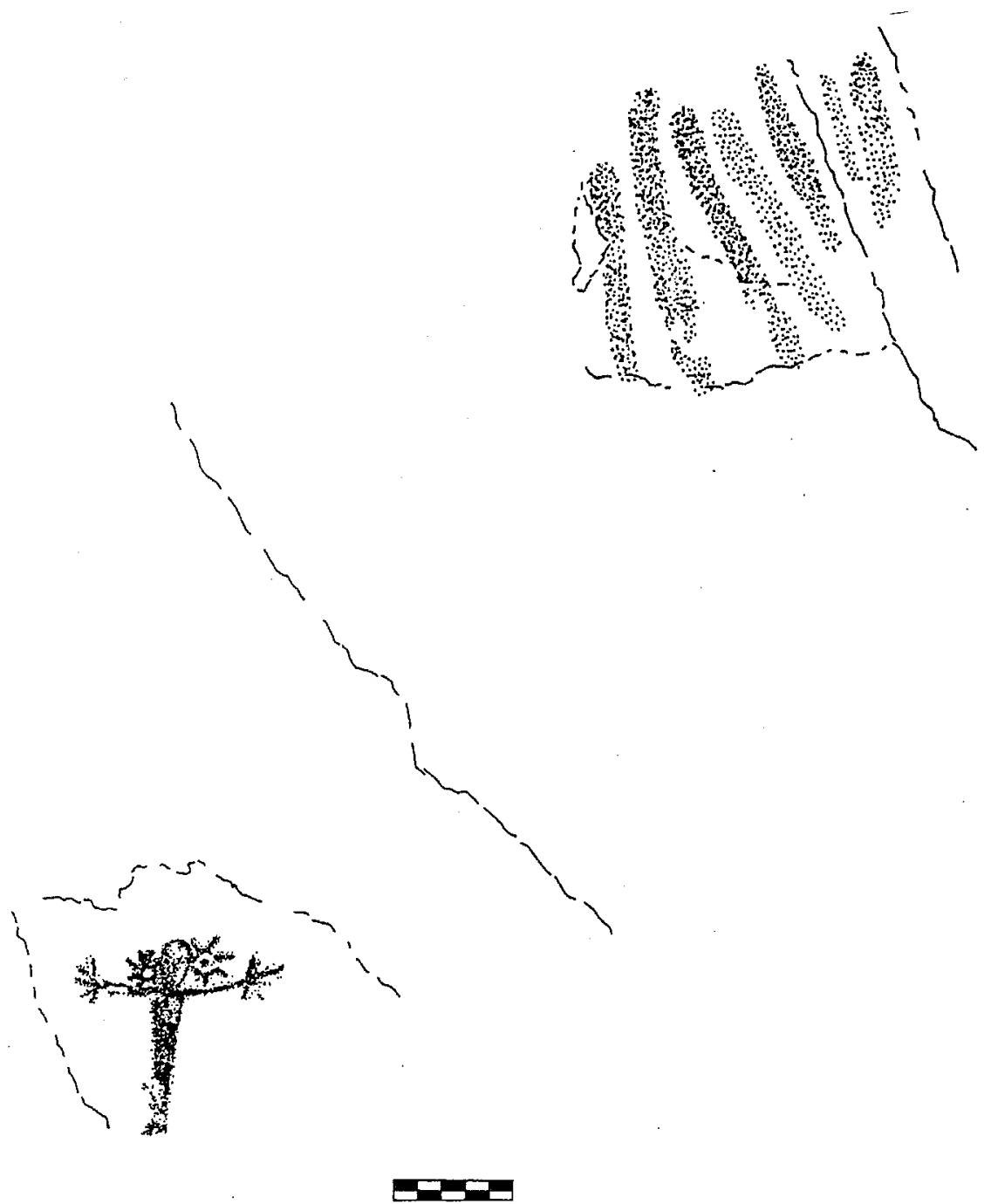

Figura 10. Moriscas V. Detalle. 
en Calderas II solamente 1. Se trata de representaciones constituidas por un trazo recto vertical en cuyos extremos superior e inferior se dibujan sendos trazos horizontales, de tal modo que sobresale tanto por arriba como por abajo el eje central vertical. En un caso se dibujan dos figuras de este tipo unidas de tal modo que constituyen una sola, por lo que podemos interpretarla como una pareja. Probablemente nos encontramos ante representaciones humanas masculinas con indicación del tronco, cabeza, brazos y piernas. La asociación de estos motivos con barras, y el hecho de que alguna de éstas esté en proceso de transformación hacia cruciforme, dada la leve indicación de ambos trazos horizontales, permite que también podamos interpretar estas barras como antropomorfos. Cruciformes son representados en los vecinos abrigos de Buitres I y $X{ }^{27}$, Pez IV ${ }^{28}$ y Morro del Valle de la Venta ${ }^{29}$.
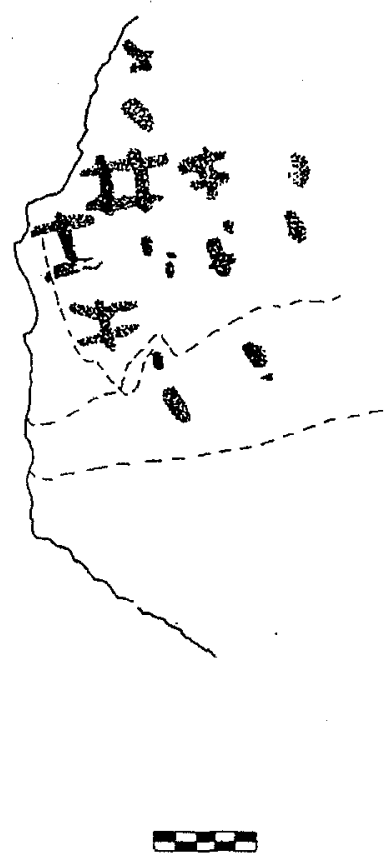

Figura 11. Calderas 1. Detalle.

\footnotetext{
BreuIL, Les peintures.., cit., vol.II, PI. XV:a, PI. XVIII:a.

Martínez Perelló, Un nuevo conjunto de pinturas..., cit., pág. 209, fig. 6.

Martinez Perelló, Arte Rupestre en Badajoz..., cit., págs. 314 y 319, fig. 7.
} 
En Montón III.3 se dibuja una figura muy similar al tipo descrito, si bien el trazo vertical no sobresale tanto por su extremo superior, quedando a medias entre el tipo cruciforme y el tipo en T. Este tipo, a veces más complejo, lo encontramos también en los abrigos Buitres $\mathrm{X}$, Morro del Valle de la Venta, Cueva Inferior de la Fuente del Peral y Pez I ${ }^{30}$.

Mención aparte merece la figura humana cruciforme asociada a dos soliformes descrita unas líneas más arriba y ubicada en el Abrigo $V$ de Las Moriscas (Fig. 10). Resulta interesante la representación de los dedos en los extremos de los trazos verticales que se dibujan a modo de brazos, ya que su disposición radial coincide en su aspecto con los dos soliformes situados a ambos lados de la cabeza, sobre los hombros. El autor insiste así en remarcar el carácter mágico-religioso-ritual de la figura, cuyo significado desconocemos. Este ídolo se plasma aislado, y tan solo unas barras se sitúan a cierta distancia en el panel sin que se pueda establecer ningún tipo de relación. En el otro extremo del abrigo se localiza la forma circular rellena de puntos dispuestos de modo ramiforme que ya hemos descrito anteriormente.

Podemos señalar la presencia de figuras pectiniformes en las tres localizaciones, con un total de 8 motivos representados que se concentran en tres abrigos: Montón II, Moriscas IX y Calderas I, con 4, 3 y 1 motivo respectivamente.

Su interpretación difiere de unas representaciones a otras, ya que, mientras el carácter zoomorfo de las figuras de Moriscas IX parece más que probable dada la indicación del cuello y cabeza del animal (Fig. 12), no ocurre lo mismo con el resto de los motivos. No se pueden descartar las interpretaciones que algunos autores hacen como símbolos representativos de lluvia ${ }^{31}$, o como la simple enumeración de barras para indicar miembros de un grupo humano, días, animales, difuntos, o cualquier otra cosa que mantenga entre sí algún tipo de relación, marcada por la barra horizontal que uniría a estos elementos en su representación pictórica. Motivos de este tipo hallamos en los abrigos Buitres $\mathrm{V}$ y $\mathrm{X}$, cuevas de Agallares y de Bercialejo, Valle de la Huerta Vieja y Pez $\mid$ y ||${ }^{32}$.

Junto a este grupo situamos el de los motivos en "pi» que en 4 ocasiones se dibujan en el Abrigo II de El Montón. En sus paneles podemos

30 Breule, Les peintures..., vol. II, cit., PI.XVIII:a; MARtinez PERElló, Arte rupestre..., cit., págs. 319-320; Un nuevo conjunto..., cit., pág. 204, fig. 2.

$31 \mathrm{KüHN}$, H. (1957): El arte rupestre en Europa, Barcelona, pág. 117.

32. Breuli, Les peintures, vol.II, cit., PI.XVII:a, PI.XVIII:a. MARTíneZ PERELlo, Un nuevo conjunto..., cit., 203-207,209-211, figs. 4,5 y 8.

- La pintura rupestre esquemática..., cit., pág. 118. 

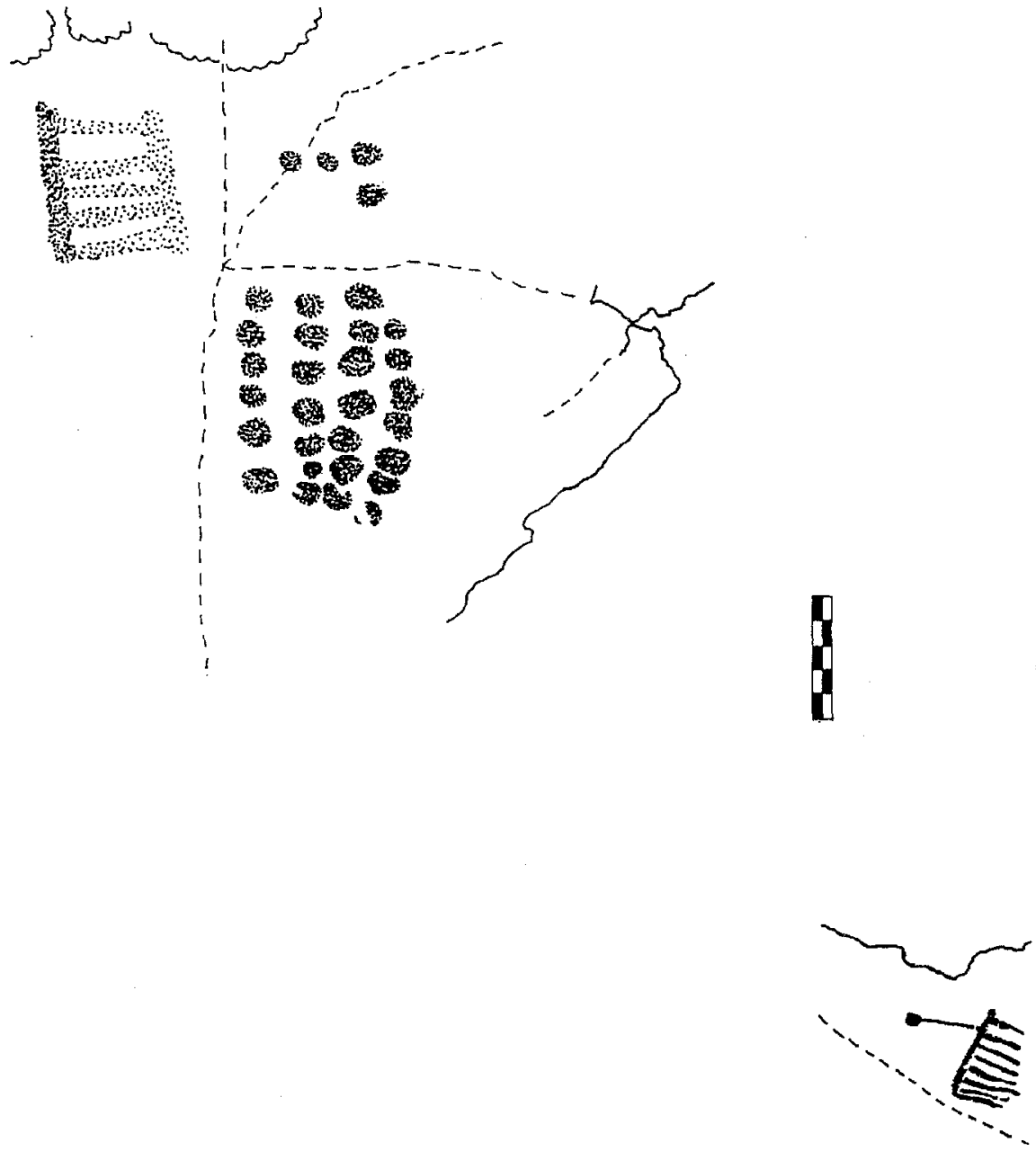

Figura 12. Moriscas IX. Detalle. 
encontrar las asociaciones pectiniforme-pectiniforme, "pi»-pectiniforme y pectiniforme-ramiforme. Los motivos en pi se diferencian de los pectiniformes en que el trazo horizontal tan solo une dos líneas verticales, mientras que en los pectiniformes une de tres en adelante. Sin embargo los problemas de interpretación son muy similares. Tal vez estas figuras en «pi» sean abstracciones de zoomorfos, o tal vez se trate de representaciones de parejas, de viviendas, etc. La simplicidad de sus líneas no nos permite aproximarnos más en su interpretación.

Existen sobre los lienzos rocosos de los abrigos VII de El Montón y III de Las Moriscas unas representaciones pictóricas de carácter antropomorfo constituidas por uno o dos triángulos y que hacen un total de 7 ejemplares. También las encontramos en Moriscas II, en dos grupos de 4 y 5 figuras (Fig. 6 y Fig. 13). Las incluimos en el tipo de idolos unitriangulares y bitriangulares de Acosta.
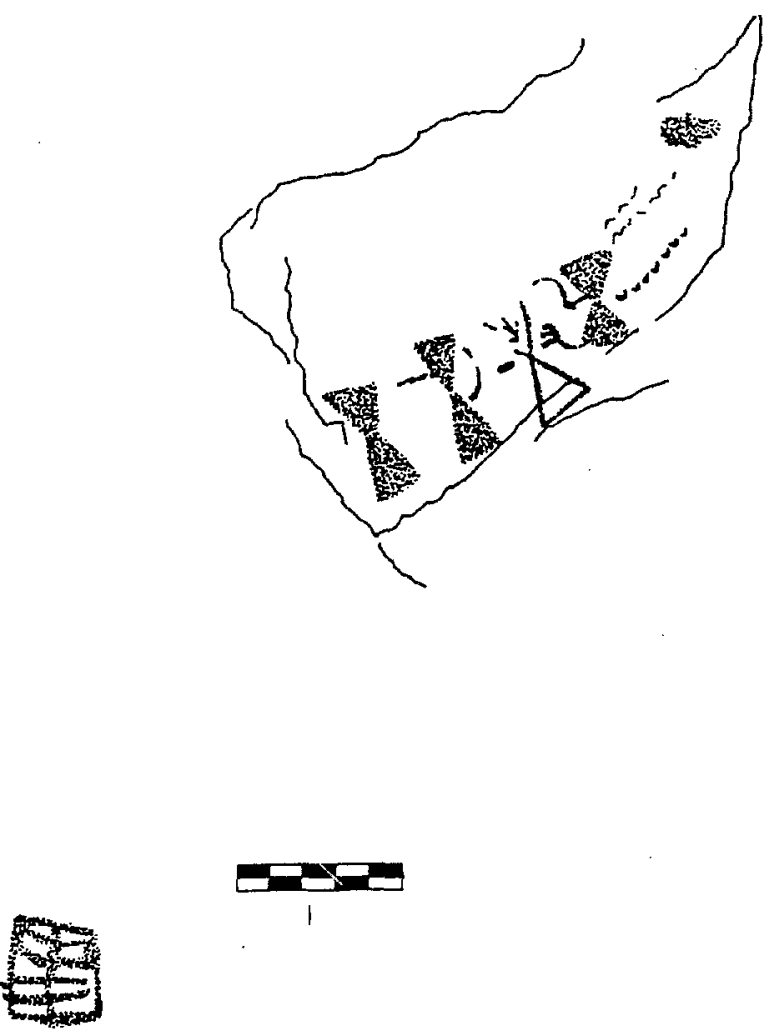

Figura 13. Moriscas II. Detalle. 
En el primer abrigo mencionado se observan, entre las colonias de líquenes que cubren la pared casi totalmente, 3 bitriangulares asociados a 3 zoomorfos cuadrúpedos que se disponen a sus pies y en los que se representan cabeza, orejas y cola con un mayor detallismo que lo habitual en los zoomorfos de esta zona (Fig. 14). Así pues en este abrigo encontramos las asociaciones de bitriangular-bitriangular y bitriangular-cuadrúpedo. Un rasgo que individualiza a estos ídolos bitriangulares es el tocado que se sitúa sobre el extremo superior de dos de ellos. Uno consiste en cuatro pequeños triángulos - dispuestos dos a dos y apuntando hacia arriba- en cada uno de los extremos del triángulo superior, y el otro se dibuja a modo de dos pequeños cuernecillos situados también en los vértices del mismo triángulo. Podríamos encontrarnos ante una escena de domesticación de animales por parte de esos antropoformos (¿representaciones femeninas?) en los que se indican ciertos atributos especiales. Desgraciadamente el penoso estado de conservación del panel, que en tiempos debió contener numerosas pinturas pues su superficie lisa y su situación le confieren un carácter ideal para realizar en él este tipo de actividades, no nos permite contemplar la escena completa por lo que la información que nos ofrece queda sesgada, condicionando su interpretación.

En Moriscas III son 4 los ejemplares, esta vez unitriangulares, que todavía se pueden contemplar pese a lo diluido de su pigmento rojizo (Fig. 15). Están formados por un triángulo coronado en su vértice por una forma
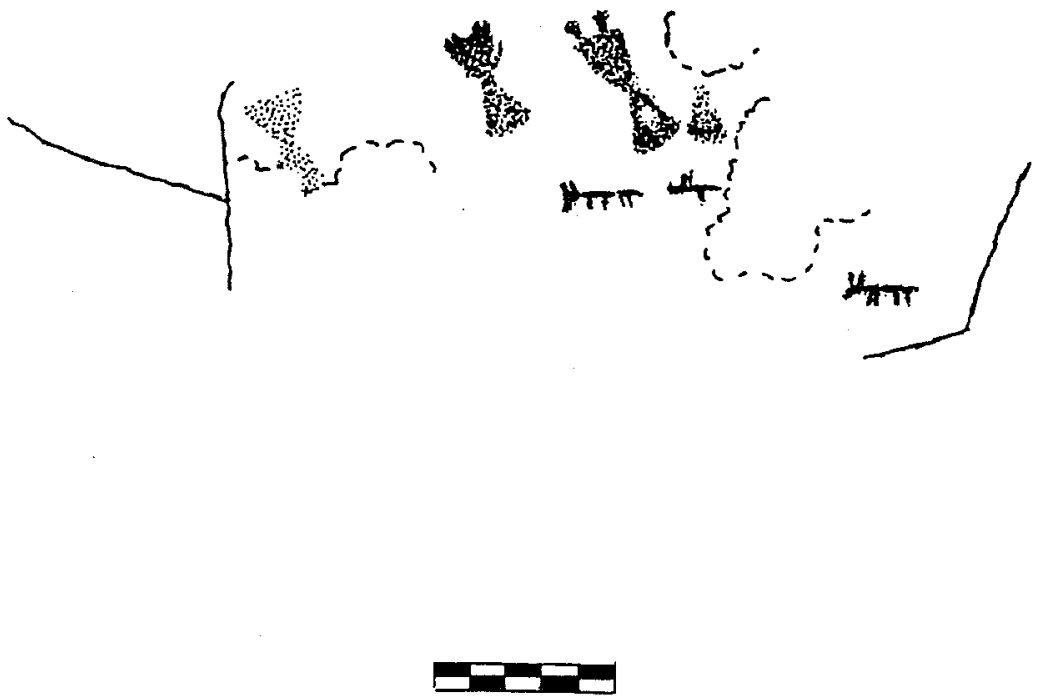

Figura 14. Montón VII. Detalle. 


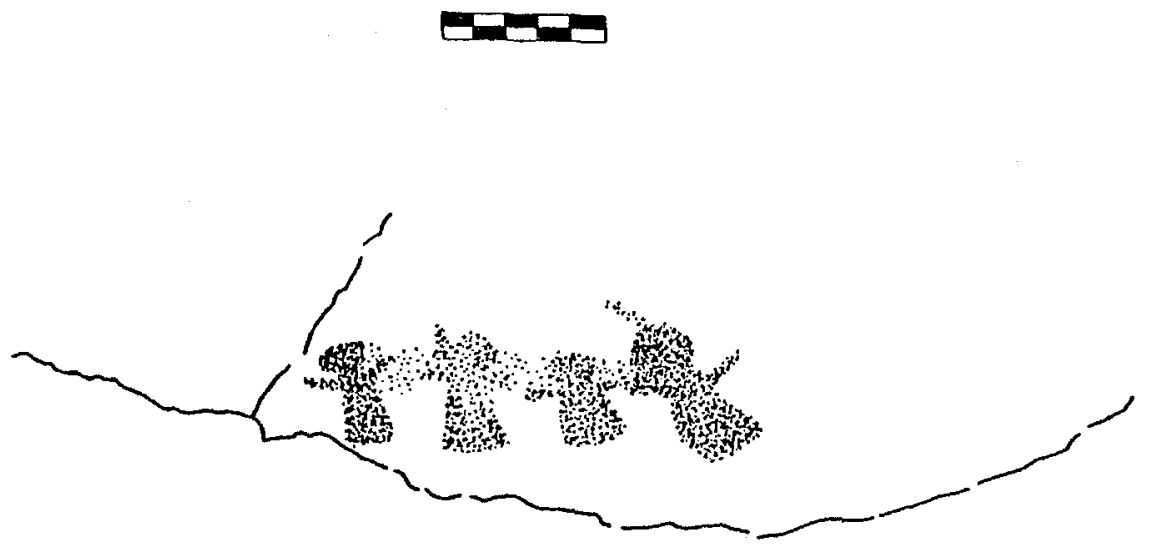

Figura 15. Moriscas III. Detalle.

circular a modo de cabeza y por dos trazos rectos que parten a derecha $e$ izquierda indicando los brazos alzados. La proximidad de las figuras hace que en ocasiones se llegue al contacto entre ellas, dando la sensación de que entrelazan sus brazos para ejecutar algún tipo de danza. No se asocian a ningún otro motivo esquemático, y en el abrigo únicamente aparecen dibujadas, a una cierta distancia, 4 barras horizontales y un tectiforme de color grisáceo.

Idolos unitriangulares y bitriangulares encontramos en los abrigos próximos de Buitres I, Estanislao ${ }^{33}$ y Cueva Superior de la Fuente del Peral ${ }^{34}$.

Incluimos entre los motivos tipo serpentiforme (que encontramos únicamente en el Abrigo III.4 de El Montón) tanto representaciones zoomorfas como líneas zigzagueantes u ondulantes cuya interpretación no resulta tan clara. Los primeros, por el detalle con que se han dibujado cabeza y cola, son fácilmente identificables con ofídios (Fig. 8). En total son 4 los

34 Martinez Perelló, La pintura rupestre esquemática..., cit., pág. 112. 
ejemplares que se representan, todos en el mismo panel y asociados a ramiformes antropomorfizados y a un esteliforme.

Representaciones de este tipo se dibujan en los abrigos de Buitres $X^{35}$, Pez I y II, Morro del Valle de la Venta y Cueva Superior de la Fuente del Peral ${ }^{36}$.

Otro tipo de motivos que observamos en este conjunto de estaciones rupestres es el de los tectiformes, siguiendo en el orden de clasificación la frecuencia de su representación.

Se dibuja en 3 ocasiones, en Montón III.3 y $\vee$ y en Moriscas $V$. En el Abrigo III.3 debemos resaltar, por lo inusual, la existencia de una superposición de trazos en color blanco dibujando una figura reticular sobre tres líneas rojas que quedan en su espacio interior (Fig. 3). Este yacimiento rupestre es interesante porque en él encontramos algunas características propias que suponen una novedad en el conjunto de abrigos de Helechal: en primer lugar, observamos una de las pocas superposiciones existentes en esta zona, además se utiliza en sus dibujos el pigmento blanco que se superpone al rojo, y finalmente vemos la asociación tectiforme-barras que nos induce a interpretar este diseño como un algún tipo de estructura o habitat que cobijaría bajo su techo a varias figuras, probablemente humanas. Aunque figuras tectiformes se representan en Buitres $V$ y X, Pez I, Gruta de la Sierra de Agallares y Cueva del Pozo Retumba ${ }^{37}$, estructuras evidentes cobijando figuras humanas las encontramos en lugares algo más apartados, como en La Asomadilla (Soria) ${ }^{38}$, en el Tajo de las Figuras (Cádiz) y en Cantal Chico (Málaga) ${ }^{39}$.

Las figuras escaleriformes se localizan en Las Moriscas.

Observamos 1 representada en Moriscas VIII y 2 en Moriscas IX. En el primero aparece como motivo único y en el segundo comparten panel con una figura en «phi», zoomorfos pectiniformes, barras y alineaciones de puntos. Su interpretación es bastante complicada. Probablemente

35 BREUIL, Les peintures..., cit., vol. II, PI. XVIII:a.

36 Martínez Perelló, Un nuevo conjunto..., cit., págs. 203-207 y págs. 209-211, figs. 4, 5 y 8.

- Arte Rupestre..., cit., págs. 321-322.

- La pintura rupestre esquemática..., cit., pág. 118.

37 BreuIL, Les peintures, vol. II, cit., PI.XVII:a, PI.XVIII:a. MARTínez Perelló, Un nuevo conjunto..., cit., 203-206, 209.

- La pintura ruprestre esquemática..., cit., págs. 120.

s8 Gómez Barrera, J.A. (1982): La Pintura Rupestre Esquemática en la Altimeseta Soriana, Soria, pág. 212, fig. 85: 8.1.3.

39 BreulL, H. y BuRkitT, M. (1929): Rock paintings of Southern Andalusia, Oxford, pág. 20, Lám.J, fig. 13-19, y pág. 82, Lám. XXXIII:3. 
podamos identificarlas con estructuras como empalizadas, trampas, escalas, etc. Se representan también en los abrigos VIII y X de Los Buitres ${ }^{40}$, en Pez I y II y en la Gruta de Agallares ${ }^{41}$.

En cuanto a las figuras animales menos esquemáticas de todo el conjunto, se reducen a los 3 cuadrúpedos en fila, probablemente cánidos, asociados a los bitriangulares situados sobre ellos, del Abrigo VII de EI Montón (Fig. 14) y a 2 cérvidos que se representan en el Abrigo IV de Las Moriscas, dándose la espalda, uno junto al otro y de diferente tamaño (Fig. 4). Las cornamentas de ambos se muestran bastante desarrolladas, correspondiendo a animales aduitos. Bajo las patas del ciervo menor, dibujado sobre los cuartos traseros del otro animal, se observa un trazo recto y horizontal, posible indicación del nivel del suelo sobre el que se asentaría el cuadrúpedo, línea que también aparece bajo un antropomorfo representado en Moriscas II.

Figuras de cuadrúpedos cuyos detalles permiten su identificación con cánidos, y además casi idénticos a los dibujados en Montón VII, encontramos en la cercana Cueva del Bercialejo, en Zarza Capilla. En esta misma cueva y en Buitres $V$ se dibujan cérvidos ${ }^{42}$.

Por último se encuentra el grupo de los indeterminados, en el que ubicamos a todas las figuras de extraña forma e imposible adscripción y a todas las manchas irregulares. Estas hacen un total de 24 figuras. Se distribuyen del siguiente modo: 9 en Montón I, 2 en Montón II, 6 en Montón III.4, 1 en Montón V, 3 en Moriscas V, 1 en Moriscas VII y 4 en Calderas III. Estas figuras indeterminadas corresponden en la mayoría de los casos a restos de posibles motivos, desaparecidos o muy incompletos.

\section{Temática:}

Observando las tipologias de las figuras y las asociaciones existentes entre ellas se puede determinar, en un brevísimo repaso muy general, la representación de una serie de actividades que reflejarían sin duda el modo de vida del pueblo que decoró de tal modo las paredes de los abrigos.

Así, se distingue en Montón VII una escena de domesticación, con la representación de cuadrúpedos asociados a antropomorfos.

40 Breull, Les peintures..., cit., vol. II, PI.XV:c y PI.XVIII.

4 Martínez Perelló, Un nuevo conjunto..., cit., págs. 203-207 y 209.

42 Martínez Perelló, La pintura rupestre esquemática..., cit., págs. 118-119, fig. 7. Breull, Les peintures..., cif., vol. II, PI. XVII:a. 
En Moriscas IV se diseñan dos cérvidos, lo que nos reflejaría probablemente la existencia de una actividad cinegética, bien como elemento importante de la economía de este pueblo o bien como elemento más bien ritual.

En Moriscas 11 se dibujan figuras bitriangulares asociadas a instrumentos agrícolas, como son una hoz y un tridente, y a líneas en zig zag que podrían interpretarse como la esquematización del agua, lo que nos hablaría de la práctica de la agricultura y de actividades de tipo ritual o ceremonial asociadas a ella.

En Moriscas II encontramos una pareja que parece mantener un vínculo sexual. Esto reflejaría la importancia de la fecundación.

En Moriscas II y III se dibujan grupos de figuras humanas triangulares y bitriangulares, con los brazos alzados en posición de oración o de danza, lo que nos acercaría al mundo de la religiosidad y creencias, en el que se realizarían danzas rituales como las que aquí parecen reflejarse; este mundo espiritual también podría estar representado en Moriscas VI, en donde se diseña una figura humana de tipo cruciforme asociada a dos soliformes a la que otorgamos el carácter de ídolo, carácter que también concedemos a los oculados que se dibujan en Moriscas I, a los halteriformes de Montón VIII y probablemente a las figuras bitriangulares tocadas con cuernos de Montón VII. Finalmente, en Montón I encontramos una serie de trazos dispuestos en torno a una serie de accidentes naturales de la roca constituyendo un diseño que podría identificarse con una máscara humana (Fig. 9).

\section{Características técnicas:}

Las pinturas rupestres esquemáticas de Helechal no ofrecen, desde un punto de vista técnico, ninguna novedad importante a la pintura rupestre extremeña y peninsular. Están realizadas mediante las técnicas de la tinta plana y lineal, ésta para los trazos más finos.

El color de los 622 motivos es fundamentalmente rojo vinoso, con leves variaciones hacia tonos más oscuros o más claros, dependiendo de la calidad del mineral utilizado para crear los pigmentos y las diferencias de intensidad en el color que existieran en estos, la calidad de la roca y su tono, y el grado de adherencia del pigmento al soporte rocoso. Esto último depende de factores como la cantidad de pigmento que se deposite, su hidratación, fosilización y procesos químicos y mecánicos que se produjeran, agentes internos inherentes a la roca y externos. Por si todo esto no fuera suficiente también influyen en la determinación del color la humedad ambiental y la luz del momento en que se efectúan estos análisis 
(esto puede variar dependiendo de la estación, el mes, el día y hasta la hora en que se realicen estas comprobaciones).

Pese a todo ésto hemos empleado para nuestros trabajos una tabla cromática ${ }^{43}$ que nos ha permitido diferenciar algunos motivos en gris, como son un ramiforme horizontal y algunas barras de Montón III.4, un tectiforme en Moriscas III, y una rueda dibujada en Moriscas VI, en la que se combinan el gris para su mitad izquierda y el rojo vinoso para la derecha. También en un tectiforme de Montón III.3 existe una combinación, en realidad superposición, de dos colores: blanco sobre rojo. Podemos establecer una existencia mayoritaria del rojo vinoso (Pantone 173u) en las figuras de este conjunto de Helechal, seguido en frecuencia por un tono algo más oscuro (180u) y por el marrón (174u). El gris (404u) es bastante escaso.

Las dimensiones de las figuras tampoco ofrecen novedades. Se mantienen dentro de lo habitual en el arte esquemático peninsular.

Los motivos de mayor tamaño son dos ramiformes dibujados en el Abrigo III.4 de El Montón ( $23 \times 19 \mathrm{~cm}$ y $12,5 \times 3 \mathrm{~cm}$ respectivamente) ${ }^{44}$, y una figura circular con el interior punteado representada en Moriscas $\mathrm{V}$ $(20 \times 20 \mathrm{~cm})$.

Pero sin duda es el Abrigo VI de Las Moriscas, con su carácter monotemático representando únicamente figuras en "phi», el que contiene los ejemplares con un tamaño medio mayor de todo el conjunto $(10 \times 7 \mathrm{~cm})$.

Las figuras más pequeñas son los cuadrúpedos de Montón VII $(1,8 \times$ $2,4 \mathrm{~cm})$ y el ramiforme del Abrigo VII o Cuevecilla de Las Moriscas $(4 \times 4$ $\mathrm{cm}$ ), aparte de los puntos (los hay de hasta $0,3 \times 0,3 \mathrm{~cm}$ ) y las barras (las menores son de $2 \times 0,2 \mathrm{~cm}$ ).

La anchura media de los trazos está en $1 \mathrm{~cm}$, pero encontramos figuras de $0,1 \mathrm{~cm}$ de espesor, como por ejemplo el serpentiforme de Montón III.4 que en la cabeza y cola se ensancha hasta alcanzar $0,4 \mathrm{~cm}$ y su altura es de $6 \mathrm{~cm}$, y el soliforme $(4 \times 4 \mathrm{~cm})$ que se dibuja en el mismo abrigo y que también presenta un grosor en su trazo de $0,1 \mathrm{~cm}$. El grosor máximo (2 $\mathrm{cm}$ ) lo encontramos en algunas barras, y muchos de los motivos de $1 \mathrm{~cm}$ de espesor alcanzan en algunos tramos $1,5 \mathrm{~cm}$.

Las figuras de mayor grosor parecen haber sido ejecutadas empleando la yema de los dedos para aplicar la pintura, mientras que para los ejemplos más finos se debe haber utilizado algún tipo de «pincel» rudimentario, como una ramita con el extremo preparado convenientemente o una pluma de ave.

43 Ver nota 9.

44 Ver nota 10. 


\section{CONCLUSIONES CRONOLÓGICO-CULTURALES}

El conjunto pictórico esquemático de Helechal se enmarca en el conjunto de arte rupestre postpaleolítico de la zona oriental de la Comarca de la Serena, en la provincia de Badajoz (que corresponde a los términos municipales de Capilla, Peñalsordo, Zarza Capilla, Cabeza del Buey y Helechal y que comprende las estribaciones orientales de Sierra Morena). Se suma a las estaciones rupestres ya estudiadas y publicadas por Breuil en esta zona en $1933^{45} \mathrm{y}$ a las descubiertas últimamente ${ }^{46}$.

El análisis detallado de las pinturas que contiene nos permite adscribirlas - por su emplazamiento, tipología, temática y características técnicas- plenamente al denominado arte esquemático. Este tradicionalmente ha sido atribuido a un periodo cronológico-cultural comprendido entre el Calcolítico y el Bronce Final ${ }^{47}$.

45 BreuIL, H. Les peintures rupestres schématiques de la Péninsule lbèrique, tomo II Bassin du Guadiana, Lagny, 1933-35. En este volumen recoge 10 abrigos en la Sierra de Los Buitres o de La Moraleja (Capilla), 3 rocas en la orilla izquierda del río Zújar: "Cueva de la Hoya de la Huerta", "Cueva del Toril de los Toros» y «El Solapo del Toril de los Toros» (Peñalsordo), en Cabeza del Buey 3 abrigos en la "Majadilla del Puerto Alonzo" (Sierra de las Cabras), dos rocas en el "Cerro Estanislao», la «Cueva de la Majadilla del Local», el «Peñón Amarillo del Callejón del Valle de los Alisos" y la "Gueva del Barranco de la Higuera» (Valle de los Alisos), finalmente en Helechal recoge 2 abrigos de Las Moriscas «Abrigo del Zarzal» y «Abrigo Superior», 2 abrigos en el Puerto de Las Ruedas y en el cerro de El Montón los abrigos del «Callejón del Peñón de las Grajas" y del «Peñón Amarillo del Olivar de Las Grajas». Hacen un total de 28 abrigos.

46 Martínez Perelló, M.I. (1988-89): Un nuevo conjunto de pinturas esquemáticas de la Sierra del Pedroso (Peñalsordo y Capilla, Badajoz). Ars Praehistorica VII-VIII, págs. 201-219. En este artículo se dan a conocer cinco nuevos abrigos en el término municipal de Capilla (cuatro en el Peñón del Pez y uno en el Castillo de Capilla) y tres abrigos inéditos en Peñalsordo: el «Abrigo de la Huerta Vieja", el "Abrigo del Collado de la Cruz Chiquita" y la "Gruta de la Sierra de Agallares".

- (1993): Arte rupestre en Badajoz. Un nuevo abrigo con pinturas esquemáticas: El Morro del Valle de la Venta (Cabeza del Buey). Revista de Estudios Extremeños, t. XLIX, núm. II, págs. 309-336. En este artículo se suma una nueva estación con arte rupestre «El Morro del Valle de la Venta» al conjunto de abrigos pintados de Cabeza del Buey. Son así ya nueve los abrigos aparecidos en la zona hasta el momento.

- (1994): La pintura rupestre esquemática en la zona oriental de la provincia de Badajoz: Estado de la cuestión. Espacio, Tiempo y Forma, Serie I, t. 6, págs. 97-132. En este trabajo se analiza el estado de las investigaciones llevadas a cabo en este área, señalando los descubrimientos de nuevas estaciones rupestres (a los ya mencionados en los artículos anteriores se suman: la cueva del Bercialejo, en Zarza Capilla, y los abrigos de Las Moriscas, El Montón y Las Calderas, en Helechal). Se realiza un estudio general de todos ellos y se presentan unas conclusiones preeliminares.

47 Acosta MARTínez, P. (1984): El arte rupestre esquemático ibérico: problemas de cronología preliminares. Homenaje a F.Jordá Cerdá, Salamanca, págs. 31-61.

Beltrán MARTínez, A. (1975-76): El problema de la cronología del arte rupestre esquemático español. Caesaraugusta, 39-40, Zaragoza, págs. 5-18.

- (1983): El arte esquemático en la Península lbérica: orígenes e interrelación. Bases para un debate. Zephyrus XXXVI. Actas del Coloquio Internacional sobre Arte Esquemático de la Península Ibérica (Salamanca, 1982), Salamanca, págs. 38-41. 
Si seguimos en un rápido recorrido la cronología señalada por algunos investigadores para ciertos motivos representados, parece que el conjunto de Helechal se sitúa en el ámbito de la Edad del Bronce: las figuras bitriangulares podrían datarse en la primera mitad del Bronce $\left.\right|^{48}$, y las tenemos presentes a finales del Bronce I y principios del Bronce II en ídolos de hueso y pizarra y en materiales cerámicos hallados, por poner algunos ejemplos, en los yacimientos de Los Millares, Vélez Blanco y la Carigüela del Piñar ${ }^{49}$.

Los ídolos oculados se sitúan por algunos autores en el III Milenio o inicios del Bronce $\mathrm{I}^{50}$, aunque este tema ya está representado en los ídolos calcolíticos hallados en Extremadura ${ }^{51}$.

Beltrán sitúa las figuras en «phi» en un momento no muy temprano de la Edad del Bronce ${ }^{52}$.

Los motivos ramiformes se inscriben también en el Bronce $1^{53}$. Las representaciones de figuras humanas tocadas con cascos de cuernos las encontramos sobre todo en las figuras grabadas en las estelas extremeñas datadas en el Bronce Final-inicios del Hierro ${ }^{54}$.

JORDÁ CERDA, F. (1983): Introducción a los problemas del arte esquemático de la Península Ibérica. Zephyrus XXXVI, Actas del Coloquio Internacional sobre Arte Esquemático de la Peninsula Ibérica (Salamanca, 1982), Salamanca, págs.

Martínez Perelló, M.I. (1993): La pintura rupestre esquemática en la zona oriental de la provincia de Badajoz: Estado de la cuestión. Espacio, Tiempo y Forma, Serie I, tomo 6, 97-132.

Ripoll Perelló, E. (1968): Cuestiones en torno a la cronología del arte rupestre postpaleolítico en la.Península Ibérica. Simposio Internacional de Arte Rupestre, (Barcelona, 1966). Barcelona, págs. 165-192.

- (1983): Cronología y periodización del esquematismo prehistórico en la Península lbérica. Zephyrus, XXXVI, Actas del Coloquio Internacional sobre Arte Esquemático de la Península Ibérica (Salamanca, 1982), Salamanca, págs. 27-35.

48 Acosta MARTíNez, P: (1968): La pintura rupestre esquemática en España. Salamanca, pág. 79.

49 Motos, F. de, (1918): La Edad Neolítica de Vélez Blanco, Com. Inv. Paleont. y Preh., Mem. núm. 19, Madrid, fig. 15:a, b y c.

Pellicer, M. (1964): El Neolítico y el Bronce de la cueva de la Carigüela del Piñar (Granada), Trabajos de Prehistoria, núm. 15, pág. 33; fig. 10:26.

50 AcostA, P. (1967): Representaciones de ídolos en la pintura rupestre esquemática española, Trabajos de Prehistoria, XXIV, pág. 22.

- La pintura rupestre..., cit., pág. 69.

51 HuRtado, V. (1978): los ídolos del Calcolítico en el Occidente peninsular, Habis 9, Sevilla, págs. 357-364.

- (1980): Los idolos calcolíticos de La Pijotilla (Badajoz), Zephyrus XXX-XXXI, págs. 165-203.

52 Beltrán Martínez, A. (1969): La Cueva de Los Grajos y sus pinturas rupestres en Cieza (Murcia), Monografias Arqueológicas VI, Zaragoza, pág. 50.

- (1972): Los abrigos pintados de La Cañaica del Calar y de la Fuente del Sabuco en El Sabinar (Murcia), Monografias Arqueológicas IX, Zaragoza, pág. 120.

${ }_{3}$ ACOSTA, La pintura rupestre..., cit., pág. 130.

54 Almagro BasCH, M. (1966): Las estelas decoradas del Suroeste peninsular, Bibl. Praeh. Hisp. VIII, Madrid, págs.178-180, fig.24 y lám.XIX, págs. 122-124, fig. 42 y lám. 
Finalmente, los cuadrúpedos esquemáticos se han situado en el Bronce I como fecha inicial ${ }^{55}$ fecha que, según Acosta, también comparten las figuras esteliformes ${ }^{56}$.

A ésto se añade un aspecto muy importante, y es la existencia en el cerro de un yacimiento arqueológico. Su prospección superficial ${ }^{57}$ nos ha aportado un total de 247 restos cerámicos. Nos referimos exclusivamente a materiales cerámicos ya que no hemos encontrado otro tipo de industria. Son cerámicas prehistóricas hechas a mano, con un solo caso de torno, sin decoración en general, con superficies alisadas y en algún caso bruñidas, pastas de color pardo, ocre, anaranjado y grisáceo, desgrasantes de minerales cuarcíticos, micáceos y arenillas, frecuentemente gruesos (de 3 a $4 \mathrm{~mm}$ ) y medios (de 2 a $3 \mathrm{~mm}$ ) y cocciones tanto reductoras como oxidantes y de formas sencillas fácilmente paralelizables con los materiales recogidos en excavaciones de yacimientos datados en el Calcolítico y en el Bronce Final, según el caso, ubicados en lugares no muy distantes, tanto en la provincia de Badajoz como en Cáceres, ya que todos responden a unas tradiciones culturales similares y a ciertos factores funcionales. Sin embargo, no se ha realizado ninguna excavación, ni en este cerro ni en toda el área próxima, que nos permita establecer con fiabilidad una secuencia cronológica.

La asociación de restos arqueológicos con las manifestaciones pintadas esquemáticas ia efectuamos basándonos en su proximidad, pero somos conscientes de que la atribución cultural derivada es extraordinariamente arriesgada. Sin embargo, se trata de los únicos vestigios materiales hallados junto a las pinturas.

Los tipos predominantes son los cuencos, vasos, platos y fuentes. Dentro de estos tipos encontramos en El Montón algunas variantes: vasos de paredes rectas, de perfil en $\mathrm{S}$, cuencos de casquete de esfera, cuencos con el borde exvasado y fuentes y cuencos con carenas.

Estas últimas son de gran importancia, pues van a servir para aproximarnos al periodo durante el cual este cerro fue ocupado. Se trata de cerámicas en las que se marca la línea de separación, la carena, entre la parte inferior y la superior. La inferior tiene forma de casquete esférico y la superior es troncocónica. Exceptuando este rasgo común las diferencias

55 Acosta, La pintura rupestre..., cit., pág.54.

56 Acosta, La pintura rupestre..., cit., pág. 137.

57 Agradecemos su colaboración en las tareas de prospección a los arqueólogos Javier Jiménez, Graciela Rodríguez y Julián García. 
morfológicas entre las piezas son acusadas: la carena puede ser alta (Fig. 16:1 y 2), media (Fig. 16:3 y 4) o baja (Fig. 16:5). El labio se presenta recto, entrante (Fig. 16:3) y además engrosado (Fig. 16:2) y exvasado (Fig. 16:4), también ligeramente cóncavo (Fig. 16:1) y muy cóncavo y exvasado superando la línea de carenación (Fig. 16:5).

El cuenco de carena baja (Fig. 16:5) localizado en los perfiles del camino abierto a los pies del cerro, responde a las formas y al aspecto característico de cerámicas que encontramos en algunos yacimientos de la provincia de Badajoz como la Dehesa del Piojo (Ribera del Fresno) ${ }^{58}$, La Palacina (Alange) ${ }^{59}$, Los Villares (Feria) en un enterramiento en cista ${ }^{60} \mathrm{y}$ la Solana del Castillo de Alange ${ }^{61}$. El paralelismo con el horizonte portugués de Atalaia ${ }^{62}$, con piezas del estrato XIV de Setefilla (Lora del Río) ${ }^{63}$ y con el mundo de las motillas manchegas ${ }^{64}$ situaría a nuestro yacimiento en un momento del Bronce Pleno.

Por otra parte, las piezas (Fig. 16:1 y Fig. 16:2) con su carenas altas acusadas, bordes ligeramente exvasados y engrosados y el fragmento de carena media (Fig. 16:3) parecen más propias del Bronce Final. Son semejantes a las formas del mundo de Cogotas $1^{65}$, localizadas también en zonas más meridionales como El Llanete de los Moros (Montoro, Córdoba) ${ }^{66}$, La Mesa de Setefilla (Sevilla) ${ }^{67}$ o en la misma provincia de Badajoz en La Solana del Castillo de Alange ${ }^{68}$. Casi con toda probabilidad estas influencias

\footnotetext{
58 Rodriguez Díaz, A. (1986): Arqueología de la Tierra de Barros, Zafra, pág. 94 y fig. 20.

59 Enriquez Navascues, J.J. (1990): El Calcolítico o Edad del Cobre de la Cuenca Extremeña del Guadiana: los poblados. Museo Arq. Prov. Badajoz, Publicaciones 2, Badajoz.

60 Gil-Mascarell, M.; Rodríguez Díaz, A. y EnRIQuez, J.J. (1986): Enterramientos en cistas de la E. del Bronce en la Baja Extremadura, Saguntum 20.

61 PAVón SoldevilLa, I. (1994): Aproximación al estudio de la Edad del Bronce en la cuenca media del Guadiana: La Solana del Castillo de Alange (1987), Cáceres, págs. 72, 74-75.

62 Schubart, H. (1965): Atalaia. Una necrópole da idade do bronze no Baixo Alentejo, Arquivo Beja XXII, fig. 15:b, fig. 17:d, y fig. 19:e.

- (1975): Die Brozezeit im Südwesten der Iberschen Halbinsel, Madr. Forsch., 9, tafel 27:238, Karte 13 y 14.

63 Auber Semmler, M.E.; Serna, M.R.ñ Escacena, J.L. y Ruiz Delgado, M.M. (1983): La Mesa de Setefilla. Lora del Río (Sevilla), Excav. Arq. en España, no 122, Madrid, págs. 51-52 y 70 , figs. $18: 18,20$ y 21.

64 NÁJera, T.; Molina, F.; Aguayo, P. y SaEz, L. (1977): Excavaciones en las Motillas del Azuer y Los Palacios (Ciudad Real), XIV CNA (Vitoria 1975), Zaragoza, págs. 503-514.

65 FERnAndez-Posse y DE ARnAIZ, M.D. (1986): La Cultura de Cogotas I, Homenaje a Luis Siret, Sevilla.

Martín de la Cruz, J.C. y Montes Zugadi, A. (1986): Avance del estudio sobre el Horizonte Cogotas I en la Cuenca Media del Guadalquivir, Homenaje a Luis Siret, Sevilla.

6s Martín de la CaUz, J.C. (1987): El Llanete de los Moros (Montoro, Córdoba), Excav. Arq. en España, no 151 .

67 Aubet, La Mesa de Setefilla..., cit., pág. 56, fig. 15:4

68 PAvón, Aproximación al estudio de la Edad del Bronce..., cit., pág. 78.
} 


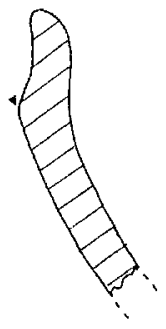

1

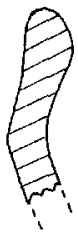

2

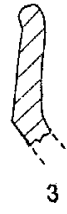

3

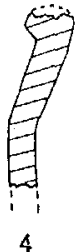

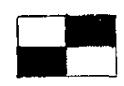
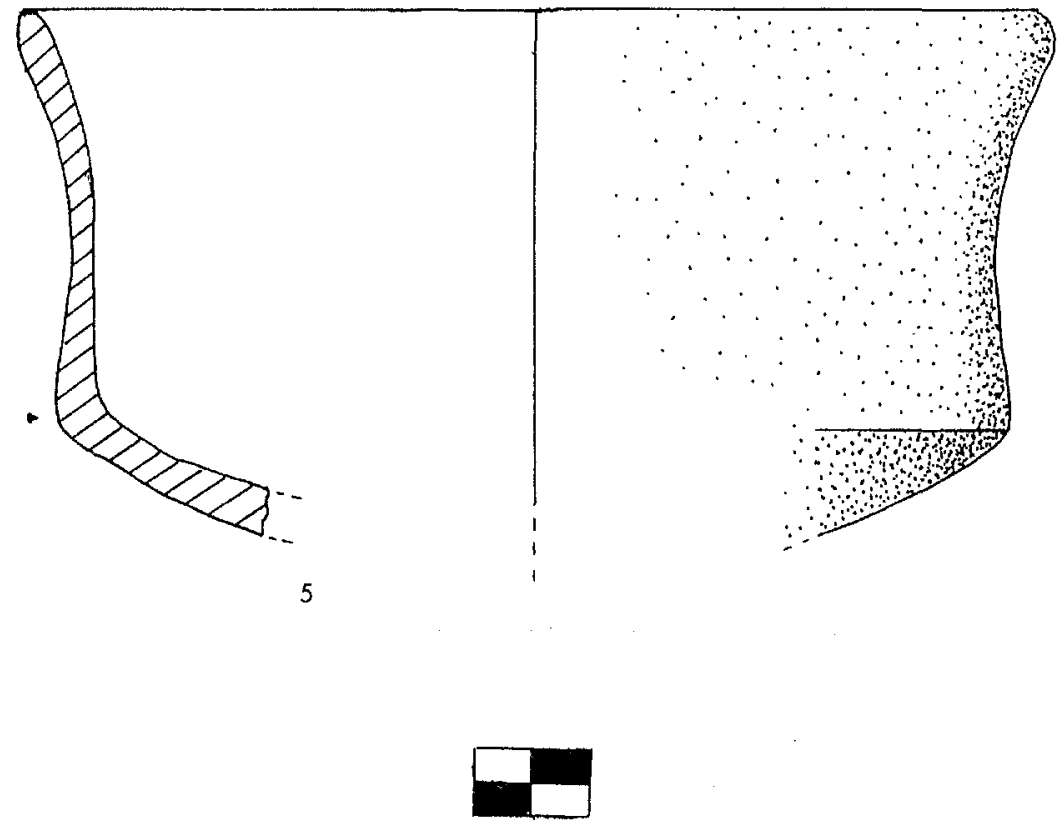

Figura 16. Cerámicas del Cerro "El Montón". 
meseteñas llegaron a la zona del Bajo Guadalquivir a través de Extremadura. Su presencia en El Montón, dado que proceden de un nivel superficial, o bien indica una ocupación del cerro también durante este momento tardío o delata una presencia temprana de elementos culturales que serán propios del Bronce Final, poniendo en evidencia la existencia de un largo proceso evolutivo desde mediados del II milenio a.C. hasta por lo menos finales de éste.

Los cuencos y vasos globulares que hallamos en este cerro responden a los tipos semiesféricos, de casquete esférico y de paredes entrantes. Las vasijas semiesféricas y las globulares de paredes entrantes, a veces con cuello recto engrosado (Fig. 17:1 a 7) no tienen demasiado valor cronológico pues se encuentran en todos los complejos cerámicos del Cobre y Bronce de la Península Ibérica.

Las cerámicas globulares de boca estrecha y bordes convexos, que denominamos de perfil en $S$, representadas en El Montón (Fig. 18:1,2 y 3), son muy características del horizonte cultural de las cistas de Huelva, parte integrante del complejo de las cistas portuguesas, y las encontramos en las cistas de Castañuelo I, Becerro I y La Ruza (Huelva) ${ }^{69}$, en las cistas del cortijo de Chichina (Sevilla) ${ }^{70}$, y en la necrópolis portuguesa de Atalaia ${ }^{71}$. También aparecen en yacimientos como el mencionado de Setefilla ${ }^{72}$.

El cuenco semiesférico de borde entrante (Fig. 17:6) está profusamente representado en yacimientos del Bronce Pleno como los estratos XIV y $X V$ de La Mesa de Setefilla ${ }^{73}$, y del Bronce Medio avanzado como las cistas onubenses de Becerro, Beas y Castañuelo ! ${ }^{74}$ y las cistas sevillanas de Chichina ${ }^{75}$. $Y$ finalmente el tipo globular con un adelgazamiento y ligero exvasamiento del labio (Fig. 18:4) lo encontramos representado en la necrópolis de Atalaia del Bronce Pleno ${ }^{76}$.

A los vasos de paredes rectas o ligeramente entrantes (Fig. 17:1 y 6 , Fig. 18:5 a 12) tampoco se les puede considerar un valor cronológico

69 Del Amo, M. (1975): Enterramientos en cista en la provincia de Huelva, Huelva: Prehistoria y Antigüedad, Madrid, pág. 146, láms. 98, 113, 114, 116118 y 119.

70 Fennández Gomez, F. et alii, (1976): Los enterramientos en cistas del Cortijo de Chichina (Sanlúcar la Mayor, Sevilla), Trabajos de Prehistoria, n 33, figs. 6, 8 y 10.

71 Shubart, Die Kultur..., cit., tafel 2E:221, 224 y 225, tafel 27:233 y 234.

72 Aubet, La Mesa de Setefilla..., cit., pág. 52, fig. 19:30 y 21:37.

73 Aubet, La Mesa de Setefilla..., cit., pág. 52, fig. 15:5-9 y fig.18:25-29.

74 DEL AMO, Enterramientos en cista..., cit., págs. 109 y ss., láms. 101, 105, 107, 109, 110, 118 y 121.

75 FERNÁNDEZ el alii: Los enterramientos en cistas..., cit., figs. 6,8 y 10.

76 Schubart, Die Kultur..., cit., tafel 26:266. 

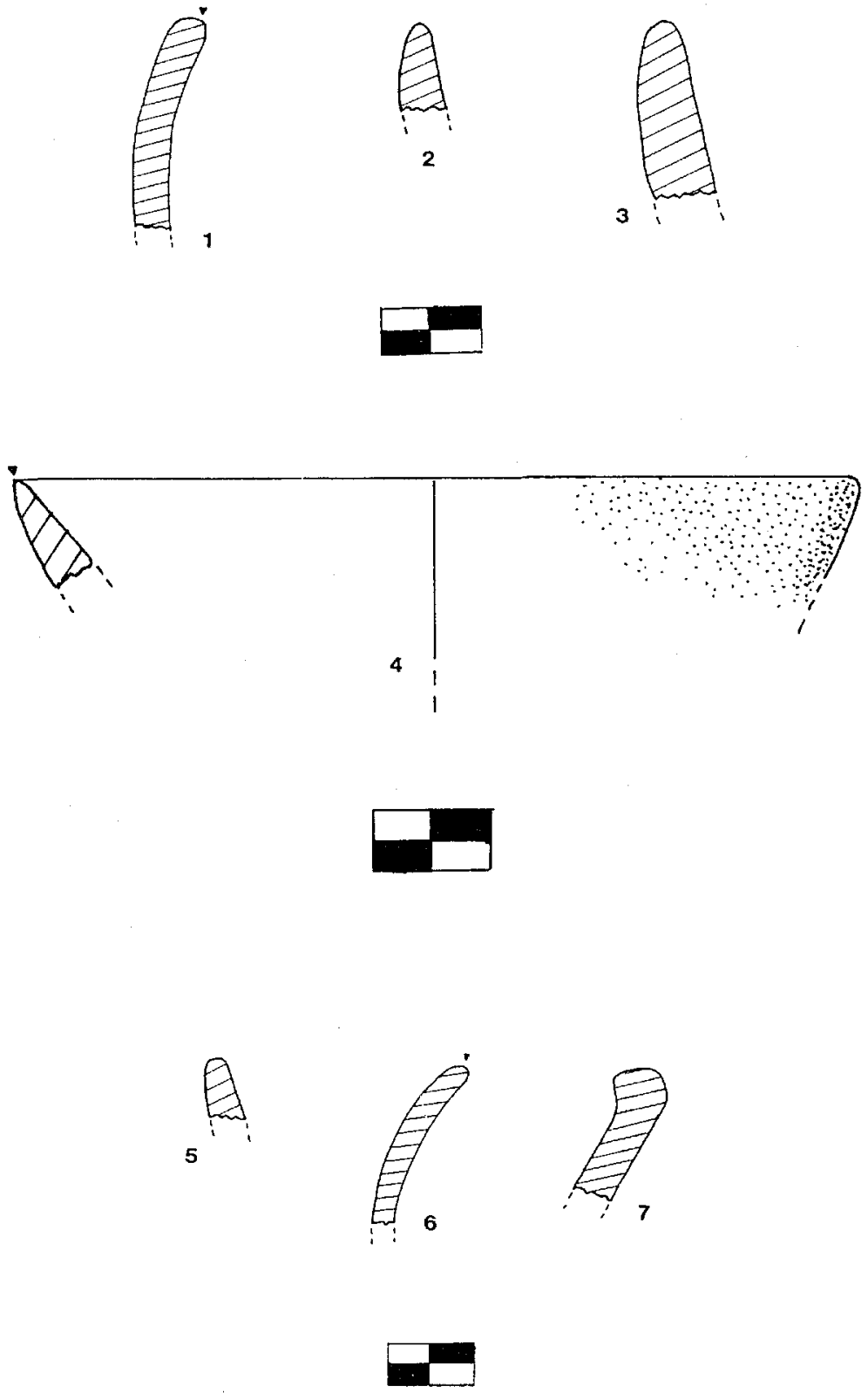

Figura 17. Cerámicas del Cerro "El Montón". 
significativo, pues los encontramos primero en contextos Calcolíticos, después en la fase de transición entre el Calcolítico y la Edad del Bronce, y finalmente en contextos del Bronce Pleno, como en La Solana del Castillo de Alange. Una pieza de El Montón (Fig. 18:13) presenta un mamelón junto al borde similar a los que aparecen en este yacimiento pacense ${ }^{77}$.

Existe un único ejemplar de plato (Fig. 18:14) con el labio ligeramente exvasado, muy similar a una pieza aparecida en la Cueva de Boquique y fechada en el Bronce Final ${ }^{78}$. Los platos de borde angrosado o reforzado son muy característicos del mundo Calcolítico del SOE, y en la provincia de Badajoz los encontramos en Araya, El Lobo, Camino de Meriendas y El Carrascalejo ${ }^{79}$, pero el ejemplar de El Montón no se asemeja a ellos.

La pieza carenada y con el labio muy acusado y exvasado (Fig. 16:4) recuerda por su forma a cerámicas ya de la Plena Edad del Hierro ${ }^{80}$.

En cuanto a la decoración, nos encontramos ante una gran mayoría de cerámicas lisas. La ausencia casi total de ornamentación en las piezas tiene algunas excepciones: la presencia de dos mamelones en sendos fragmentos cerámicos (Fig. 18:13). Estos son característicos del Calcolítico Inicial, sin embargo también se mantienen durante el Calcolítico Pleno y los seguimos encontrando, más escasos, en el Bronce Pleno, por lo que no presentan valor cronológico.

La incisión es otra técnica decorativa empleada en una de las piezas de El Montón. Se trata de incisiones oblícuas y paralelas en la parte superior del borde (Fig. 18:15). En el yacimiento sevillano de Mesa de Setefilla encontramos una pieza con una decoración muy similar en un contexto del Bronce Pleno ${ }^{81}$.

La impresión también se practica, al menos, en un ejemplar (Fig. 18:16). Se trata de una franja horizontal por encima de la línea de carena constituida por una serie de motivos con forma de $U$, probablemente realizadas con el extremo de una caña. Este tipo de decoración lo encontramos en un fragmento de galbo hallado en el yacimiento de La Muralla, en la comarca de Alcántara (Cáceres), considerado como del Bronce Final ${ }^{82}$.

77 Pavon, Aproximación al estudio de la Edad del Bronce..., cit., pág. 88.

78 Rivero de LA Higera, M.C. (1972-73): Materiales inéditos de la Cueva del Boquique, Zephyrus, $\mathrm{n}^{\circ} 23 / 24$, fig. $19, \mathrm{n}^{\circ} 78$.

79 EnRIQUez: El Calcolítico o Edad del Cobre..., cit., pág. 198, figs. 18 y 19.

80 Martín Bravo, A.M. (1993): El poblamiento de la Comarca de Alcántara (Cáceres) durante la Edad del Hierro, Complutum 4, págs. 337-360, fig. 11.

81 AUBET, La Mesa de Setefilla..., cit., pág.57, fig. 17:17 y 20:34.

82 Martín Bravo, El poblamiento de la Comarca de Alcántara..., cit., fig.10:6. 


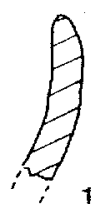

1
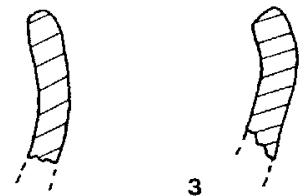

4

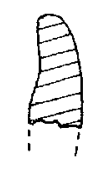

3

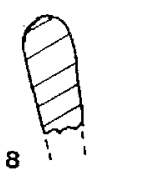

9

6

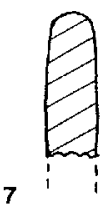

.
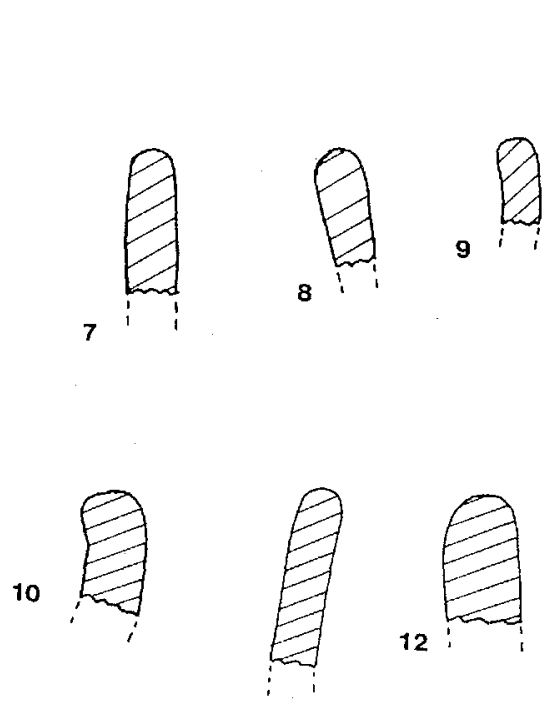

11
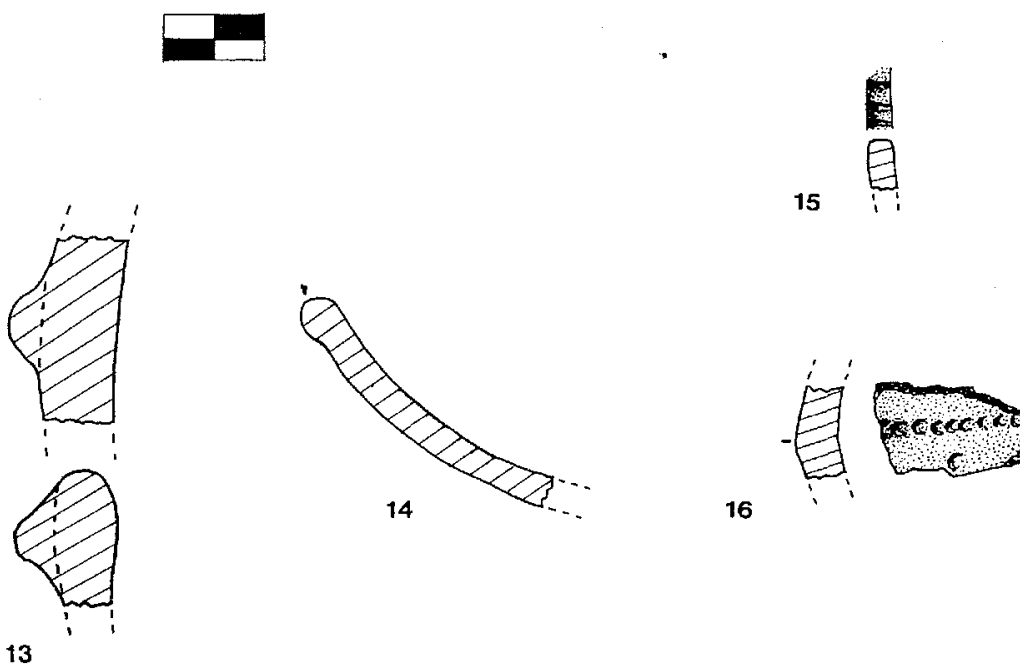

Figura 18. Cerámicas del Cerro "El Montón". 
Sin embargo la impresión como técnica decorativa no tiene por si misma un valor cronológico, ya que es utilizada desde el Neolítico y está muy difundida durante el Calcolítico y en épocas posteriores.

En conclusión, aunque el carácter superficial de la recogida de muestras en El Montón determina la hetereogeneidad de las piezas, lo cierto es que el «ambiente» general que destilan las cerámicas allí obtenidas, a pesar de que no hemos encontrado restos líticos ni metálicos, responde a un Bronce Pleno, con algunos rasgos propios de la fuerte tradición calcolítica y del Bronce Final. Más que como muestra de una ocupación anterior y posterior del cerro creemos que pone en evidencia en este período del Bronce Pleno una presencia tardía de elementos culturales propios del período Calcolítico y temprana de elementos del Bronce Final, como muestra del largo y lento proceso evolutivo transcurrido durante todo el II milenio a.C.

El asentamiento de El Montón probablemente estuvo en la cima del cerro ya que las cerámicas han sido halladas allí y rodadas por sus laderas. Debió tratarse de un pequeño poblado de apariencia pobre, dada la escasez del material arqueológico, constituido por chozas ubicadas en la cima del cerro o adaptadas a los abrigos naturales, ya que al menos en uno de ellos hemos encontrado restos cerámicos. Su carácter perecedero y la actual vegetación existente en el lugar impide que se puedan observar a simple vista restos constructivos, aunque tras una cuidadosa exploración se distinguen entre los afloramientos cuarcíticos de la cima pequeñas zoras llanas rellenas de piedra menuda que podrían corresponder a los restos de las cabañas, cerradas o delimitadas probablemente por muretes. Sería necesario efectuar una excavación para determinar las dimensiones y características del poblado.

Lo que resulta indudable es que se trata de un lugar de fácil defensa, puesto que se encuentra muy bien protegido al ubicarse en la cima del cerro y sobre unos riscos verticales, y también de control y dominio visual de un amplio territorio. Se domina desde allí el paso entre las sierras de Tiros y de la Rinconada - donde se encuentra el pueblo de Almorchón, lugar de procedencia del célebre carrito votivo-, siendo este paso una vía natural que atraviesa la cadena de sierras y comunica la comarca cordobesa de Los Pedroches con la comarca extremeña de La Serena. Desconocemos el trazado de los caminos prehistóricos y e incluso el patrón de asentamiento en esta zona, pero es innegable que debieron existir ciertos puntos obligados de paso determinados por las características orográficas ${ }^{83}$. $Y$ el interés por

s3 Galán Domingo, E. (1994): Estelas, Paisaje y Territorio en el Bronce Final del Suroeste de la Peninsula lbérica, Complutum 3, págs. 28-30. 
las comunicaciones que parece incluso predominar sobre las características defensivas de los lugares de asentamiento es propio de los habitats de la Edad del Bronce ${ }^{84}$.

Dada la relativa escasez del material arqueológico hallado en la prospección superficial, sin restos que nos indiquen una actividad metalúrgica y con la mayoría de materiales cerámicos que parecen ser coetáneos, podríamos estar ante un asentamiento sin demasiada perduración en el tiempo, propio de una sociedad con una economía principalmente ganadera, a tenor del medio ambiente en el que se sitúa, y con poca densidad de población. El valle, más fértil y recorrido por algunos arroyos, proporcionaría la oportunidad de practicar la agricultura y de obtener agua para hombres $y$ animales. A pesar de la abundancia de abrigos y covachos con pinturas rupestres se observa una relativa escasez de motivos pintados, sin superposiciones ni paneles complejos, lo que, de ser coetáneas al poblamiento del cerro, nos apuntaría también en la dirección de una ocupación no muy dilatada en el tiempo. Aunque no podemos asegurar que las gentes que habitaron ese cerro sean las mismas que realizaron las pinturas rupestres nos parece, con las debidas reservas, lo más probable. Un dato interesante es que los abrigos utilizados como soportes para pintar no son adecuados para el albergue de rebaños, puesto que o bien el espacio de que disponen es mínimo o los escarpes rocosos impiden o dificultan sobremanera el paso de los ganados hasta ellos. Es posible, pues, que los abrigos posean la dimensión de santuario, al menos en algunos casos ya que cada yacimiento rupestre en sí es una entidad diferente y no podemos hacer extensible el mismo sentido a absolutamente todas las estaciones rupestres.

84 Almagro Gorbea, M. (1977): El Bronce Final y el Periodo Orientalizante en Extremadura, Bibliotheca Praehistorica Hispánica, vol XIV, Madrid, pág. 489. 